\title{
Genome-wide analysis of H4K5 acetylation associated with fear memory in mice
}

C Sehwan Park ${ }^{1,3^{*}}$, Hubert Rehrauer ${ }^{2}$ and Isabelle M Mansuy ${ }^{1,3}$

\begin{abstract}
Background: Histone acetylation has been implicated in learning and memory in the brain, however, its function at the level of the genome and at individual genetic loci remains poorly investigated. This study examines a key acetylation mark, histone $\mathrm{H} 4$ lysine 5 acetylation ( $\mathrm{H} 4 \mathrm{~K} 5 \mathrm{ac}$ ), genome-wide and its role in activity-dependent gene transcription in the adult mouse hippocampus following contextual fear conditioning.

Results: Using ChIP-Seq, we identified 23,235 genes in which H4K5ac correlates with absolute gene expression in the hippocampus. However, in the absence of transcription factor binding sites 150 bp upstream of the transcription start site, genes were associated with higher H4K5ac and expression levels. We further establish H4K5ac as a ubiquitous modification across the genome. Approximately one-third of all genes have above average H4K5ac, of which $\sim 15 \%$ are specific to memory formation and $\sim 65 \%$ are co-acetylated for H4K12. Although H4K5ac is prevalent across the genome, enrichment of $\mathrm{H} 4 \mathrm{~K} 5 \mathrm{ac}$ at specific regions in the promoter and coding region are associated with different levels of gene expression. Additionally, unbiased peak calling for genes differentially acetylated for H4K5ac identified 114 unique genes specific to fear memory, over half of which have not previously been associated with memory processes.

Conclusions: Our data provide novel insights into potential mechanisms of gene priming and bookmarking by histone acetylation following hippocampal memory activation. Specifically, we propose that hyperacetylation of H4K5 may prime genes for rapid expression following activity. More broadly, this study strengthens the importance of histone posttranslational modifications for the differential regulation of transcriptional programs in cognitive processes.
\end{abstract}

Keywords: ChIP-Seq, Contextual fear conditioning, Gene bookmarking, Gene priming, H4K5 acetylation, Learning and memory

\section{Background}

The formation of memory requires highly orchestrated gene expression programs for the establishment and the stabilization of memory traces over time. These programs are initiated during learning and can persist for several hours $[1,2]$. Whole genome expression studies have shown that some of these programs are needed for basal homeostatic cellular functions, while others are specific for cognitive functions [3-5]. The composition and regulation of transcriptional programs however may depend on the

\footnotetext{
* Correspondence: cpark@list.mavt.ethz.ch

'Department of Health Science and Technology, ETH Zürich, Zürich,

Switzerland

${ }^{3}$ Brain Research Institute, Medical Faculty of the University of Zürich, Zürich, Switzerland

Full list of author information is available at the end of the article
}

strength and duration of training. Its well known, for example, that practice or repeated training of a skill or concept can improve memory for the subject. Multiple training sessions required to form strong memory traces may, therefore, be associated with increased gene expression or the reinforcement of existing transcriptional programs, such as those necessary for structural changes to strengthen synaptic circuits [6-10]. How this is induced at the level of chromatin and which genes are targeted by epigenetic processes remains poorly understood.

With the emergence of the post-genomic era, recent studies in the field of learning and memory have investigated the implication of chromatin remodeling in cognitive processes. Several studies have revealed that chromatin remodeling plays a critical role in memory formation [9,11-14]. Chromatin remodeling is a complex molecular

\section{Biomed Central}

(c) 2013 Park et al.; licensee BioMed Central Ltd. This is an Open Access article distributed under the terms of the Creative Commons Attribution License (http://creativecommons.org/licenses/by/2.0), which permits unrestricted use, distribution, and reproduction in any medium, provided the original work is properly cited. 
and structural process that involves the dynamic regulation of nucleosomes through different epigenetic mechanisms including histone posttranslational modifications (PTMs), DNA methylation and RNA interference [15-17]. In the rodent brain, several histone PTMs are rapidly induced and are associated with altered gene transcription following training. Acetylation of lysine 9 and 14 on H3 (H3K9ac, H3K14ac), of lysine 5, 8 and 12 on H4 (H4K5ac, H4K8ac, and $\mathrm{H} 4 \mathrm{~K} 12 \mathrm{ac}$ ), and of lysine $5,12,15$, and 20 on $\mathrm{H} 2 \mathrm{~B}$ (H2BK5ac, H2BK12ac, H2BK15ac, and H2BK20ac), increases in the hippocampus following contextual fear conditioning (CFC) $[4,11,18,19]$, a well-established behavioral paradigm for the establishment of contextual fear memory. Moreover, inhibition of histone deacetylases (HDACs) by HDAC inhibitors such as suberoylanilide hydroxamic acid (SAHA), sodium butyrate, valproic acid or trichostatin A can enhance memory and rescue deficits in contextual memory in rodents [4,12,20-25].

Although these studies provide strong evidence that histone acetylation is modulated by memory formation, a global assessment of histone acetylation at the level of the genome and the mechanism with which it regulates gene expression in memory processes is lacking. Using a genome-wide approach, we examined the distribution of H4K5ac, a mark of active chromatin implicated in transcriptional re-activation of post-mitotic cells through gene bookmarking [26], and its role in regulating transcriptional activity following the establishment of contextual fear memory in the adult mouse $[4,13]$. We propose that gene bookmarking may also be relevant in the hippocampus following learning, whereby genes may be primed for rapid induction through activity-induced histone acetylation. Using chromatin immunoprecipitation followed by deep sequencing (ChIP-Seq) and bioinformatics analysis, we show that H4K5ac in the hippocampus is prevalent throughout the genome and is a mark characteristic of actively transcribed genes. Motif analysis for conserved transcription factor (TF) binding sites (TFBS), however, reveal that gene expression depends on the enrichment of H4K5ac at consensus TFBS in the promoter and proximal to the TSS. We also identify a unique set of genes differentially acetylated for $\mathrm{H} 4 \mathrm{~K} 5$ and functionally associated with memory processes. Based on our findings, we propose a potential mechanism for priming genes through activitydependent hyperacetylation of $\mathrm{H} 4 \mathrm{~K} 5$ in the promoter upon learning.

\section{Results}

Fear memory induces H4K5ac in the hippocampus in a training-dependent manner

To examine the epigenetic and transcriptional profile of genes associated with memory formation in the hippocampus, we trained adult mice on a CFC paradigm (Figure 1A). We chose CFC because it is a robust, long-lasting learning paradigm in which memory for a context can persist for more than one year after a single training session $[27,28]$. Mice were exposed to a novel context in which they received a foot-shock, either once (Day 1) or twice on two consecutive days (Day 1 and Day 2), then tested for fear memory 24 hours later (Day 3). After a single foot-shock, the animals expressed a significant freezing response (47.2 \pm 16.5\%; $\mathrm{p}<0.001$ ) compared to control mice (After Shock, FC Day 1; Figure 1B) that was maintained when tested 24 hours later $(47.3 \pm 10.0 \%$; $<0.01)$ (Test Day 2; Figure 1B). However, with a second training session on day 2 , the freezing response was increased further by $20 \%(67.4 \pm 14.2 \%$; $p$ $<0.001$ ) when tested 24 hours later (Test Day 3; Figure 1B). In control mice, freezing on days 2 and 3 compared to day 1 (Before Shock) was significant ( $p<0.01$ and $\mathrm{p}<0.05$, respectively), but was not significant compared to day 1 (After Shock), which is the measure by which we make all comparisons. It is also worth noting that control mice plateau on day 2 while FC mice continue to have higher freezing.

FC has been associated with transcriptional programs that are activated within 1 hour after conditioning, and that persist for up to 6 hours $[3,29]$. Subsequent training, however, may increase gene expression, recruit additional genes to reinforce the memory, or prime existing transcriptional programs for rapid induction of genes for synaptic strengthening. Since memory formation has been associated with histone acetylation in the brain, we examined whether memory performance correlates with higher acetylation levels following additional training sessions. We determined the level of H4K5ac, a PTM recently implicated in gene bookmarking, and increased with FC and object recognition memory tasks $[4,13]$, following one or two days of CFC. Western blots show that H4K5ac was increased approximately 3 -fold in the hippocampus 1 hour after one CFC session. With two conditioning sessions, H4K5ac level was increased 4.6-fold over controls following a memory test on day 3 (Figure $1 \mathrm{C}$ ), suggesting that H4K5ac induction is proportionate to the amount of training. H4K5ac was examined 1 hour after memory test on day 3 because 1) gene expression is activated within 1 hour following fear conditioning and memory retrieval [30-32], 2) memory is consolidated or reconsolidated within 6 hours [3,29,32], 3) histone acetylation decreases to baseline levels within 2-4 hours $[4,33], 4)$ memory for the context is enhanced by an additional training session, and 5) H4K5ac levels are higher at this time point.

\section{Distribution of H4K5ac across the genome and within genes}

Previous studies have shown the association of histone acetylation at promoters of a restricted set of canonical genes involved in memory $[4,9,13]$, but to date, genomewide data are limited. Here, we used ChIP-Seq to determine the distribution of H4K5ac across the genome, followed by 

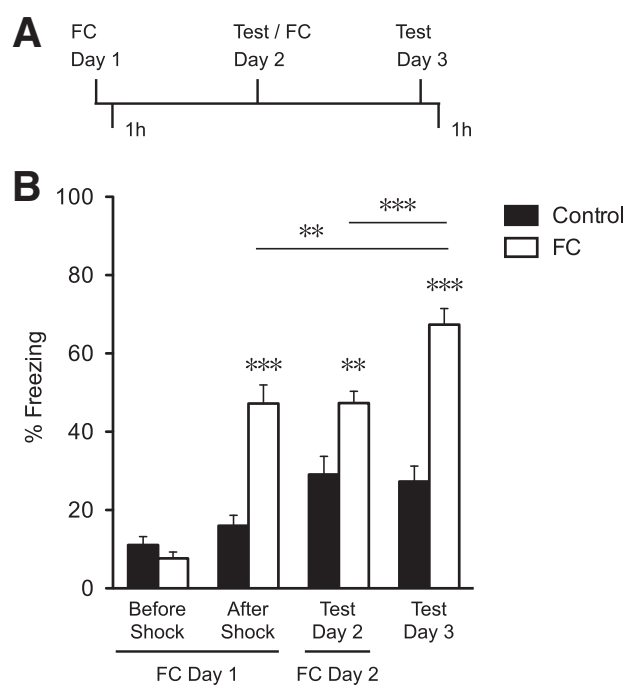

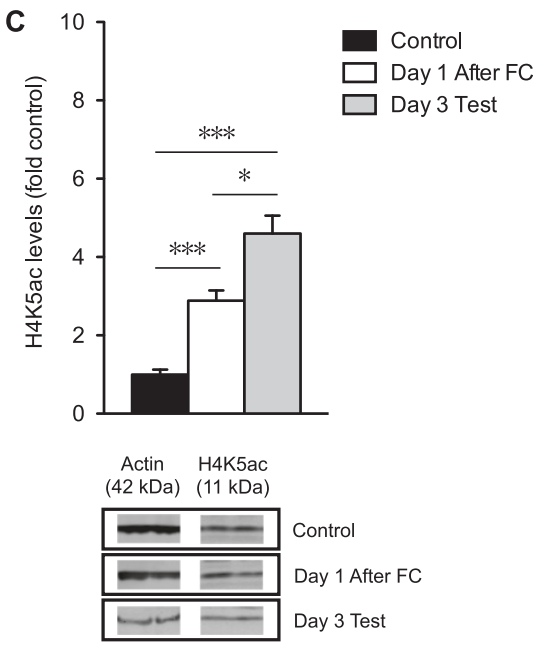

Figure 1 Contextual fear memory and its association with H4K5ac in the hippocampus. (A) Scheme of the behavioral experiment. Mice were trained on contextual fear conditioning (CFC) on day 1 (FC Day 1), tested 24 hours later on day 2 (Test Day 2), or conditioned again immediately following the test (FC Day 2), and tested again 24 hours later on day 3 (Test Day 3). Hippocampi were collected either one hour following FC Day 1 or one hour following Test Day 3. (B) Fear memory was measured as the freezing response before and after the foot-shock (shock) on FC Day 1, after re-exposure to the context on day 2 (Test Day 2), and after re-exposure to the context on day 3 in fear-conditioned ( $F C ; n=12$ ) and in non-fear-conditioned controls (Control; $n=11$ ). (C) Quantitative analysis and representative immunoblots of H4K5ac levels in nuclear fractions from whole hippocampus in controls one hour after context on day 1 (Control, $n=4$ ), one hour after CFC on day 1 (Day 1 After FC; $n=4$ ), or one hour after the memory test on day 3 (Day 3 Test; $n=3$ ). Samples derived for immunoblots were processed in parallel using actin for normalization and run on two different gels. Error bars indicate SEM. ${ }^{*} p<0.05,{ }^{* *} p<0.01,{ }^{* * *} p<0.001$.

de novo identification of genes associated with H4K5ac after CFC (after 2 training sessions) in the mouse hippocampus.

Analysis of H4K5ac distribution showed enrichment of reads in the promoter and coding sequence (CDS) of H4K5ac-ChIP samples compared to IgG-IP samples in both FC (Figure 2A and 2B) and controls (Figure 2D and 2E), an increase of 19\% (59 million read) and 17.7\% (55 million reads), respectively. The targeted enrichment of $\mathrm{H} 4 \mathrm{~K} 5 \mathrm{ac}$ to gene bodies is consistent with the proposed role of this PTM in transcriptional regulation. Analysis of $\mathrm{H} 4 \mathrm{~K} 5 \mathrm{ac}$ in genic regions revealed higher acetylation upstream of the transcription start site (TSS), spanning the CDS and extending down to the transcription termination site (TTS) compared to IgG-IP samples (Figure 2C and $2 \mathrm{~F})$. Specifically, there was a prominent peak of $\mathrm{H} 4 \mathrm{~K} 5 \mathrm{ac}$ in the promoter region approximately $800 \mathrm{bp}$ upstream of the TSS, as well as in the CDS $1 \mathrm{~kb}$ downstream of the TSS. H4K5ac distribution was similarly enriched in the control group (Figure 2D), suggesting that learning does not change the overall profile of this PTM in the hippocampus. IgG-IP samples showed low coverage in both groups (Figure $2 \mathrm{C}$ and $2 \mathrm{~F}$ ) and, thus, are appropriate input controls for $\mathrm{H} 4 \mathrm{~K} 5 \mathrm{ac}-\mathrm{ChIP}$ sequence reads.

To determine whether the observed profile was specific for $\mathrm{H} 4 \mathrm{~K} 5 \mathrm{ac}$, we compared it with $\mathrm{H} 4 \mathrm{~K} 12 \mathrm{ac}$, another histone PTM associated with fear memory, from a publicly available dataset [4]. Although H4K5ac and H4K12ac datasets could not be directly compared due to the different
CFC training protocols used, the increase of both H4K5ac and H4K12ac immediately following CFC and the higher levels of $\mathrm{H} 4 \mathrm{~K} 5 \mathrm{ac}$ after two training sessions, suggest that histone acetylation is a consistent marker of memory formation. As with H4K5ac, our analysis of H4K12ac revealed a similar bimodal peak centered at the TSS which was restricted to approximately $\pm 1 \mathrm{~kb}$ relative to the TSS but did not extend into the CDS and TTS as with H4K5ac (Figure 2G). Moreover, H4K12ac had lower enrichment in the promoter than in the CDS, in contrast to H4K5ac, which was largely enriched in the promoter. We were unable to compare H4K12ac controls, as ChIP-Seq controls for sample and experimental conditions for H4K12ac were not available in the public release of this dataset. Together, these data suggest different occupancy and potentially different modes of transcriptional regulation by $\mathrm{H} 4 \mathrm{~K} 5 \mathrm{ac}$ and H4K12ac following learning [34].

\section{H4K5ac as a marker of actively transcribed genes in the adult hippocampus}

We then examined the relationship between H4K5ac and gene transcription using a publicly available whole mouse genome microarray dataset (Agilent) for gene expression immediately after CFC in the mouse hippocampus [4]. We reasoned that because gene expression occurs within 1 hour of both memory consolidation and reconsolidation $[3,29-32,35]$, this dataset was appropriate to determine the association between H4K5ac and global gene expression. 


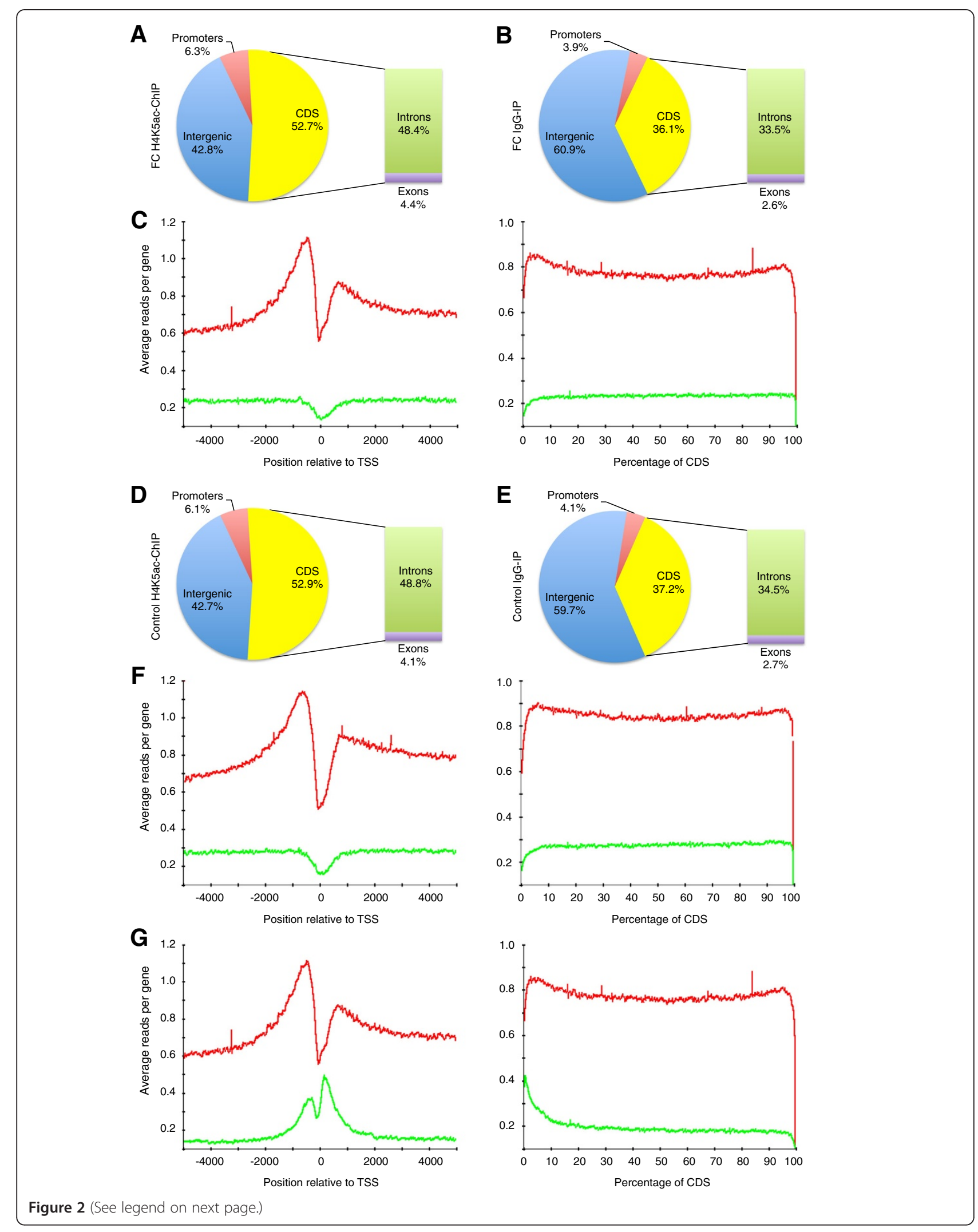


(See figure on previous page.)

Figure 2 Distribution of H4K5ac in the genome and its profile relative to the TSS. (A) Distribution of reads from H4K5ac with respect to intragenic regions including promoter, CDS (introns and exons) and intergenic regions in the hippocampus after CFC compared to (B) mock lgGIP. Promoters were defined as $5 \mathrm{~kb}$ upstream of the TSS, the CDS as regions between the TSS and TTS, and intergenic as regions excluding gene bodies. Reads spanning the transcription start site that match both a promoter and transcript are counted twice, thus, leading to total reads greater than $100 \%$. (C) Profile of reads for H4K5ac (red) and IgG-IP controls (green) across \pm 5 kb relative to the TSS (left) and spanning the CDS as a percentage of reads averaged over all genes (right). (D) Distribution of reads for H4K5aC and (E) IgG-IP by genomic regions in the absence of CFC (Control). (F) Profile of reads for H4K5ac (red) or lgG-IP (green) in Control. Distribution profiles for H4K5ac after 2 days CFC (red) compared to (G) H4K12ac immediately after 1 CFC session (green) [4]. Window analyses were obtained using EpiChIP [48].

The 18,023 genes form the expression dataset were ranked by level of expression (from lowest to highest) in FC compared to naïve controls (Figure 3A) and plotted against the average coverage of $\mathrm{H} 4 \mathrm{~K} 5 \mathrm{ac} \pm 5 \mathrm{~kb}$ relative to the TSS. The level of gene expression was found to correlate to H4K5ac enrichment such that the highest expressed genes had the highest coverage for $\mathrm{H} 4 \mathrm{~K} 5 \mathrm{ac}$, while the least expressed genes had the lowest coverage (Figure $3 \mathrm{~B}$ and 3C; Additional file 1: Figure S3A and 3D). This applied to both groups regardless of training, suggesting that $\mathrm{H} 4 \mathrm{~K} 5 \mathrm{ac}$ is a general feature of expressed genes. We also confirmed that H4K12ac correlated with the level of gene expression (Figure 3D; Additional file 1: Figure S3B). There was no correlation between gene expression and IgG-IP coverage (Additional file 1: Figure S1A and 1B). These results indicate a clear association between both $\mathrm{H} 4 \mathrm{~K} 5 \mathrm{ac}$ and H4K12ac and gene expression.

We then identified genes acetylated above average and performed a cross-wise comparison between experimental groups. Based on the average promoter read count of 45 in our dataset, we considered genes with more than 50 reads in the promoter as above average. From a total of 23,235 genes in the dataset, 7,103 genes were identified in the FC group, and 7,708 genes in the control (Figure 3E). Using this criteria, 742 genes (15.1\%) were specific for FC, 1,273 genes (21.8\%) were specific for control, and 6,029 genes ( $85 \%$ of $\mathrm{FC}$ and $78 \%$ of control) were common to both groups. We then looked at whether genes with above average H4K5ac after 2 days of CFC were also associated with H4K12ac after one session of CFC. Using an adjusted threshold of 10 reads in promoter due to the lower average coverage, approximately 9 reads in promoter, in the H4K12ac dataset, we identified 4,259 unique genes with above average H4K12ac, of which 2,772 genes (65\%) overlapped with genes with above average $\mathrm{H} 4 \mathrm{~K} 5 \mathrm{ac}$ in $\mathrm{FC}$, and 2,846 genes $(67 \%)$ with above average $\mathrm{H} 4 \mathrm{~K} 5 \mathrm{ac}$ in controls (Figure 3E; Additional file 1: Table S1). 2,440 genes overlapped all three groups using this criteria.

The results of these analyses extend our findings that in control conditions most nucleosomes are not only acetylated for H4K5 above the average of all genes, but are also acetylated for H4K12. Interestingly, nearly two-thirds of genes with above average H4K12ac after one session of CFC was found to overlap with above average H4K5ac after 2 days of CFC or context. This suggests that the same set of genes, associated with H4K12ac and induced immediately after CFC, may be upregulated following reinforced training, regardless of the associated histone acetylation used to identify the genes. It also suggests that the same set of genes may be activated after initial learning, during the formation of contextual fear memory, and after memory retrieval, independently of the CFC paradigm.

\section{H4K5ac is associated with both promoter and coding regions}

Nucleosome occupancy studies have shown that acetylated and methylated histones are enriched in the promoter of highly expressed genes, but subsequently removed or replaced in the CDS [36-38]. To investigate the positional effect of nucleosomes with H4K5ac on transcription, we clustered genes based on their acetylation profile $\pm 2 \mathrm{~kb}$ relative to the TSS. Five H4K5ac clusters were identified in FC: one in the CDS (cluster 1), one with relatively no enrichment (cluster 2), and three in the promoter (clusters 3, 4, and 5) (Figure 4A). Genes with $\mathrm{H} 4 \mathrm{~K} 5 \mathrm{ac}$ that feature in either the promoter or the CDS (clusters 1 and 3-5) constituted a larger proportion of highly expressed genes, while genes with relatively no enrichment (cluster 2) accounted for the largest proportion of genes with low expression (Figure 4B). Genes clustered for $\mathrm{H} 4 \mathrm{~K} 5 \mathrm{ac}$ in controls had profiles and cluster contributions relative to expression comparable to FC (Additional file 1: Figure S2A and 2B). For H4K12ac-clustered genes, we obtained two in the promoter (clusters 2 and 5) and two in the CDS (clusters 1 and 3), which contributed to a greater proportion of highly expressed genes compared to the non-enriched cluster (cluster 4) (Figure 4C and 4D). In contrast, IgG-IP-clustered genes, which were not enriched for H4K5ac, had equal distribution in low, moderate, and highly expressed genes, regardless of training or the histone mark (Figure 4E and 4F; Additional file 1: Figure S2C and 2D). Promoter, CDS, and 3'-UTR-associated genes correlated with $\mathrm{H} 4 \mathrm{~K} 5 \mathrm{ac}$ and $\mathrm{H} 4 \mathrm{~K} 12 \mathrm{ac}$, with and without CFC, but did not correlate with IgG-IP clusters (Additional file 1: S3A and 3E).

These findings suggest that $\mathrm{H} 4 \mathrm{~K} 5 \mathrm{ac}$ in the promoter and/or CDS may be a feature of highly expressed genes. To validate this observation, we examined the profile of 

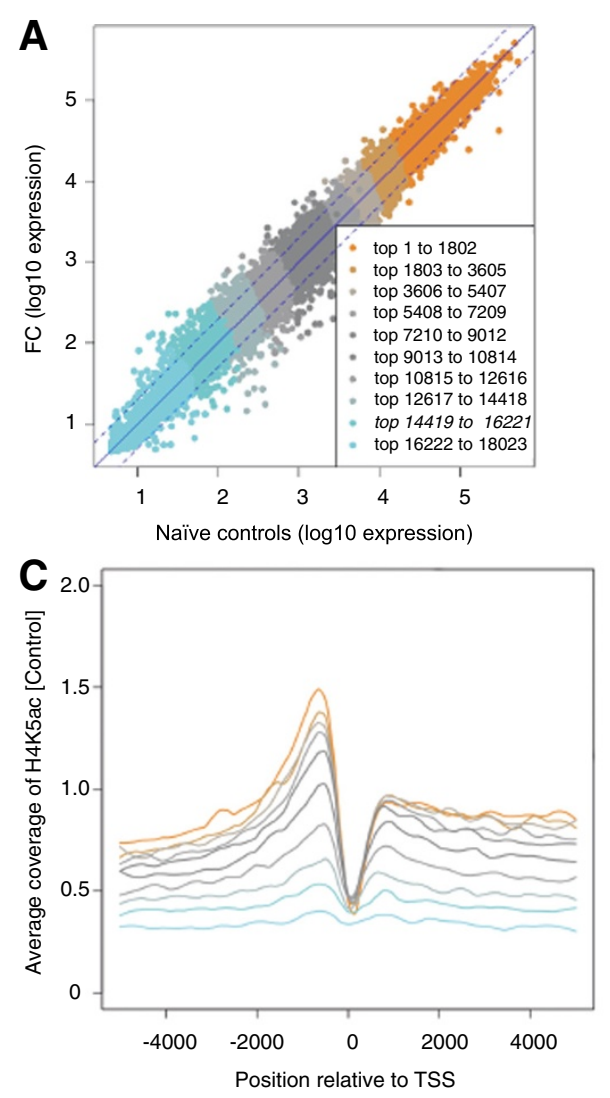
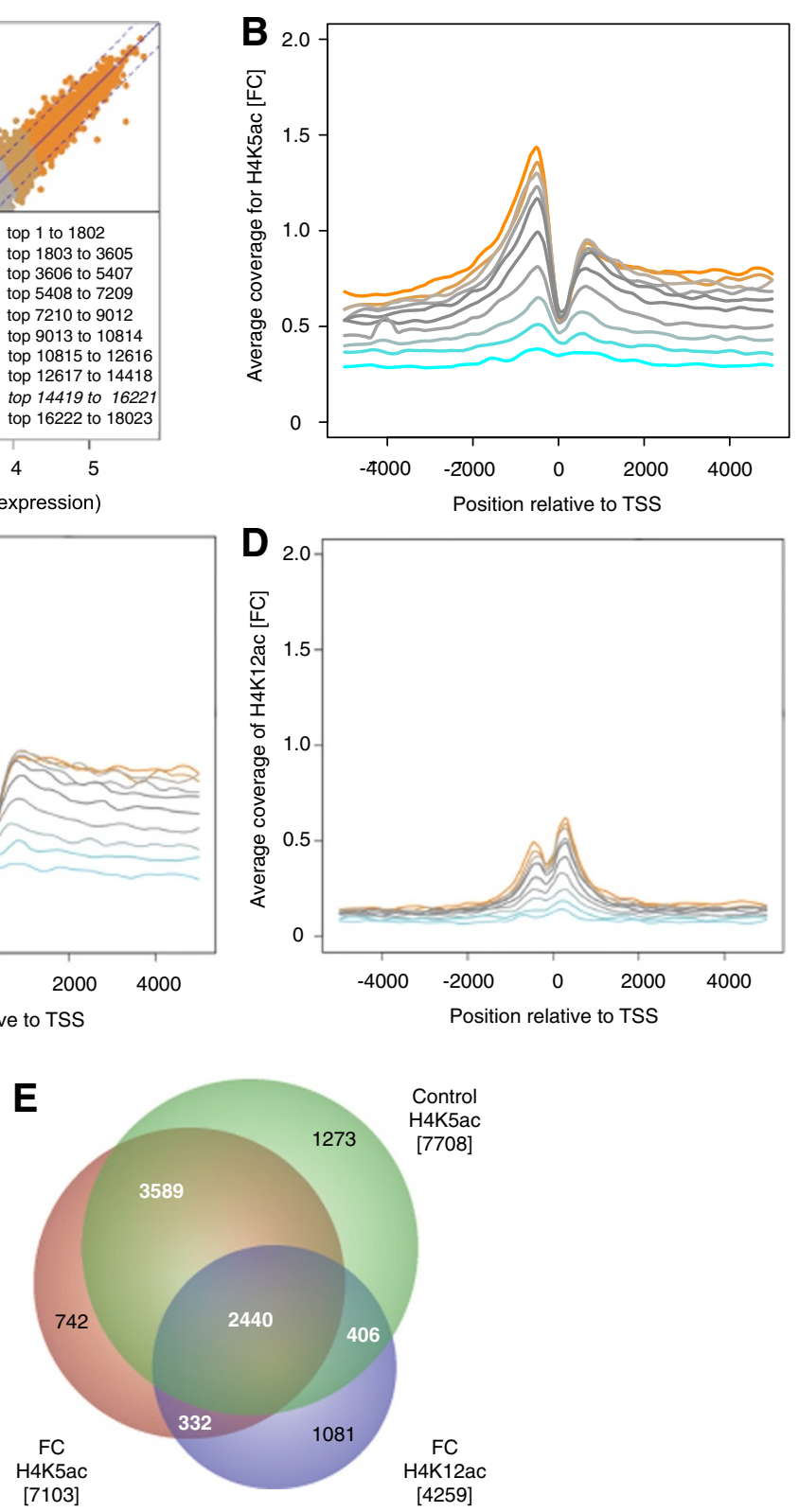

Figure 3 Qualitative assessment of H4K5ac and gene expression. (A) Expressed genes in the adult mouse hippocampus 1 hour after CFC compared to naïve controls are ranked from the lowest (cyan) to the highest expressed (orange) into 10 equal bins (1801 genes). Genes ranked by expression are correlated to average coverage for $\mathrm{H} 4 \mathrm{~K} 5 \mathrm{ac}$ in (B) FC and (C) control mice re-exposed to the context on day 3, or to (D) H4K12ac immediately after CFC on day 1; average read coverage $\pm 5 \mathrm{~kb}$ relative to the TSS. (E) Venn diagram of unique and overlapping genes identified by acetylation above the average across all genes: with an $\mathrm{H} 4 \mathrm{~K} 5 \mathrm{ac}$ threshold of greater than 50 reads in promoter, and a threshold of greater than 10 reads in promoter for H4K12ac.

H4K5ac in Sfi1 and Phactr3, two representative genes differentially acetylated for $\mathrm{H} 4 \mathrm{~K} 5 \mathrm{ac}$ in CFC and involved in cell division in mitotic cells and in memory processes $[39,40]$, respectively (Additional file 1: Table S2). In Sfi1, Phactr3, and Phactr3 splice variants, H4K5ac was targeted specifically to the CDS (green) (Figure $4 \mathrm{G}$ and $4 \mathrm{H}$ ). For Sfi1, H4K5ac was also highly enriched in the adjacent CDS of Pisd-ps1/3 (blue; Figure 4G), and downstream of the TTS in an intergenic region preceding the CDS of Eif4enif1 (pink; Figure 4G). In contrast, the CDS of Eif4enif1 and Drg1 showed dramatically lower H4K5ac. The overlap of H4K5ac in the CDS of Sfi1 and Pisd-ps1/3 translated to similar expression levels for Sfi1 (15.19; shown as $\log 2$ expression and hereafter) and Pisd-ps1/3 (14.72) but not for Eif4enif1 (11.48) or Drg1 (12.44), which had lower enrichment for H4K5ac. For Phactr3, H4K5ac 


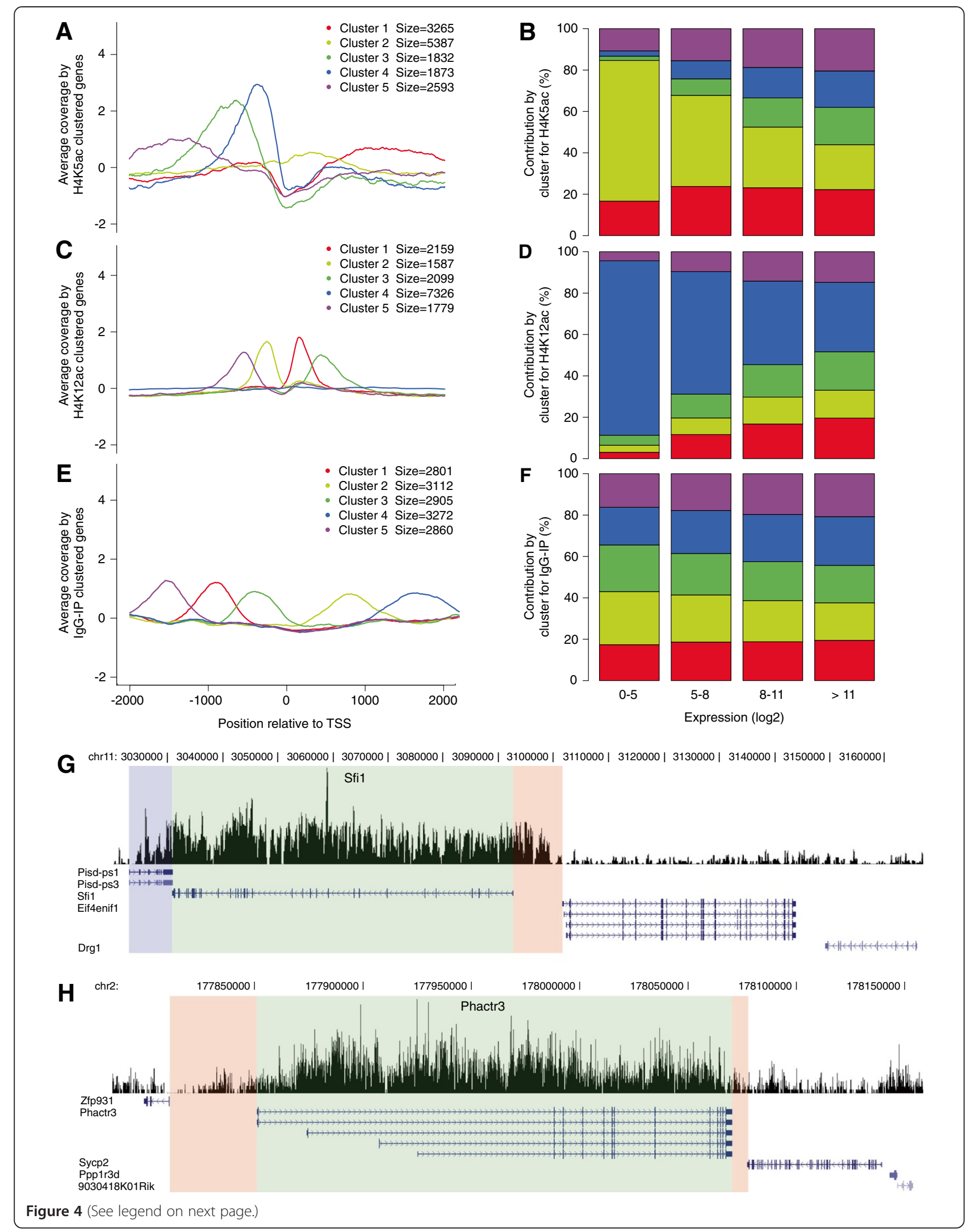


(See figure on previous page.)

Figure 4 H4K5ac enrichment in the promoter and CDS. (A) Genes acetylated for H4K5 after CFC are clustered based on acetylation profiles over $\pm 2 \mathrm{~kb}$ relative to the TSS. Clusters 3 (green), 4 (blue), and 5 (violet) occur in promoter regions, cluster 1 (red) occurs in the CDS, and cluster 2 (yellow) is unenriched for H4K5ac. (B) Contribution of gene clusters with respect to levels of gene expression show higher contribution of clusters enriched for H4K5ac with higher expression. (C) Clustering of genes acetylated for H4K12ac after CFC generated clusters 2 (yellow) and 5 (violet) in the promoter region, clusters 1 (red) and 3 (green) in the CDS, and cluster 4 (blue) is unenriched for H4K12ac. (D) The contribution of clusters enriched for H4K12ac is also higher with higher gene expression levels. (E) Clustering of genes obtained from IgG-IP controls after CFC result in uniformly distributed clusters including clusters 1 (red), 3 (green), and 5 (blue) in the promoter region, and clusters 2 (yellow) and 4 (blue) in the CDS. (F) IgG clusters show no change in contribution with increasing gene expression levels. (G, H) Custom tracks are shown for $\mathbf{G})$ Sfil (chr11:3073466-3095466) and H) Phactr3 (chr2:177908053-177930053), as identified by both MACS and SICER for genes differentially acetylated for H4K5 in FC over control. A gene contiguous to Sfi1 (Pisd-ps1/3) is highlighted in blue, the CDS is highlighted in green, and adjacent intergenic regions in pink. Neighboring genes (Eif4enif1, Drg1, Zfp931, Sycp2, Ppp1r3d, and 9030418K01Rik) are shown to emphasize H4K5ac enrichment in the vicinity of peak-called genes. Splice variants for Phactr3 (Refseq) are annotated below the track. Customized wig tracks were visualized in the UCSC Genome Browser.

coverage was lower in intergenic and CDS of neighboring genes Zfp931, Sycp2, and Ppp1r3d (pink; Figure 4H). The effect of H4K5ac on gene expression was also clearly evident for Phactr3 (15.07) and neighboring genes, Zfp931 (11.42), Sycp2 (3.97), and Ppp1r3d (11.51), which show lower expression levels. This provides further evidence that the level of H4K5ac enrichment in the CDS is directly proportional to the level of gene transcription.

\section{TF binding sites proximal to the TSS increase the statistical probability of H4K5ac-nucleosome occupancy in the promoter}

We next examined whether high levels of gene expression associated with $\mathrm{H} 4 \mathrm{~K} 5 \mathrm{ac}$ is linked to permissible TF binding. We scanned the promoter region $2 \mathrm{~kb}$ upstream of the TSS for conserved TFBS, and computed the percentage of expressed genes with H4K5ac at that position (Figure 5A). For expressed genes, the percentage of acetylated genes was significantly lower across all positions with a consensus TFBS compared to positions without a known TFBS. Unexpressed genes accounted for approximately $20 \%$ of genes with H4K5ac. Our assumption is that having a TFBS at a specific position, on average, increases the probability that TF binding occurs at that position relative to a random sequence position in the presence of H4K5ac. To refine our search and identify regions in the promoter where TF binding may affect $\mathrm{H} 4 \mathrm{~K} 5 \mathrm{ac}$ occupancy, we profiled the coverage of H4K5ac on all genes, on genes with a TFBS at 500 bp, $800 \mathrm{bp}$ or $1100 \mathrm{bp}$ upstream of the TSS, and on genes with no TFBS $100 \mathrm{bp}$ upstream of the TSS (Figure $5 \mathrm{~B}$ ). Using the average coverage of $\mathrm{H} 4 \mathrm{~K} 5 \mathrm{ac}$ of all genes as baseline, we observed that the presence of a TFBS at position $-500 \mathrm{bp}$ or $-800 \mathrm{bp}$, and $-1100 \mathrm{bp}$ resulted in modest a reduction in $\mathrm{H} 4 \mathrm{~K} 5 \mathrm{ac}$ relative to baseline coverage at that position. However, genes with no TFBS upstream of $100 \mathrm{bp}$ resulted in significantly higher $\mathrm{H} 4 \mathrm{~K} 5 \mathrm{ac}$ in both the promoter and CDS, approximately $\pm 1 \mathrm{~kb}$ relative to the TSS.
Based on the increase of H4K5ac coverage in the absence of a TFBS upstream of $100 \mathrm{bp}$, we focused our analysis in this region, proximal to the TSS. We compared the contribution of acetylated gene clusters (Figure 4A, 4C, 4E; Additional file 1: Figure S2A and 2C) in the presence or absence of a TFBS relative to $150 \mathrm{bp}$ of the TSS: either no TFBS present in the promoter (within $2 \mathrm{~kb}$ of the TSS) or no TFBS, one TFBS, or multiple TFBS $150 \mathrm{bp}$ upstream of the TSS (Figure 5C-E; Additional file 1: Figure S4A and 4B). Gene clusters with relatively no enrichment for $\mathrm{H} 4 \mathrm{~K} 5 \mathrm{ac}$ or $\mathrm{H} 4 \mathrm{~K} 12 \mathrm{ac}$ constituted a larger proportion of genes regardless of whether a TFBS was present or not (cluster 2, yellow; Figure 5C; cluster 4, blue; Figure 5D). However, in the presence of at least one TFBS within $150 \mathrm{bp}$ of the TSS (no TFBS > 150), the contribution of cluster 4 for $\mathrm{H} 4 \mathrm{~K} 5 \mathrm{ac}$ in FC (blue, nearest the TSS in the promoter; Figure $4 \mathrm{~A}$ and $5 \mathrm{C}$ ), cluster 3 for $\mathrm{H} 4 \mathrm{~K} 5 \mathrm{ac}$ in control (green, nearest the TSS in the promoter; Additional file 1: Figure S2A and 4A), and cluster 1 for H4K12ac after CFC (red, nearest the TSS in the CDS; Figure 4C and 5D) increased from approximately $10 \%$ to $20 \%$, compared to the same clusters when no TFBS was present. To a lesser extent, cluster contribution was also increased in the presence of one TFBS $150 \mathrm{bp}$ upstream of the TSS, but was diminished in the presence of multiple TFBS. These observations provide novel insight into $\mathrm{H} 4 \mathrm{~K} 5 \mathrm{ac}-\mathrm{mediated}$ regulation of gene transcription and support the notion that TF binding and acetylation are mutually exclusive in the promoter [41]. However, $\mathrm{H} 4 \mathrm{~K} 5 \mathrm{ac}$ is increased when TF binding occurs proximal to the TSS.

The observed increase in acetylation and transcription at proximal TFBS may be attributed to the recruitment of transcriptional machinery including TFs and RNA polymerase II, which is also known to occupy positions near the TSS in actively transcribed genes [42]. Additionally, recent ENCODE studies have shown that a set of TFs is strongly associated to positions proximal to the TSS and that transcriptional initiation is determined 


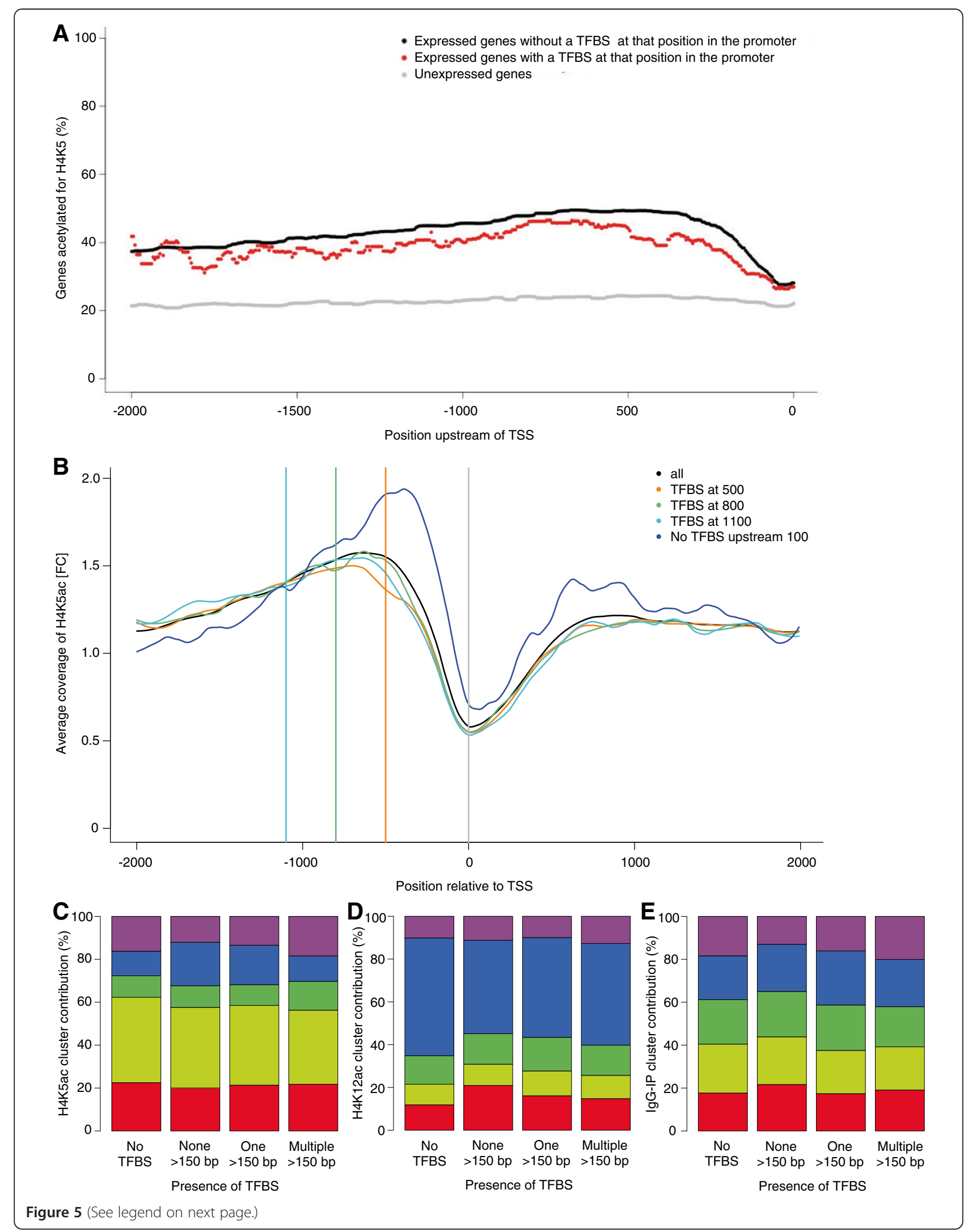


(See figure on previous page.)

Figure $5 \mathrm{H} 4 \mathrm{~K} 5 \mathrm{ac}$ in the presence of TF binding sites relative to the TSS. (A) Percent of expressed genes acetylated for H4K5 by CFC with (red) or without (black) a TFBS at that position in the promoter, $2 \mathrm{~kb}$ upstream of the TSS in 5 bp increments. Lines are smoothed with a running median of width 10. Given that a gene can be acetylated at multiple sites in the promoter regardless of whether it is expressed or not, the percentage of acetylated genes at a specific position can be greater than 100\%. Percent of unexpressed genes that are acetylated are plotted in gray. (B) Average read coverage of H4K5ac by CFC, \pm 2 kb relative to the TSS, for all genes (black), genes with a TFBS present 500 bp (orange), $800 \mathrm{bp}$ (green), or $1100 \mathrm{bp}$ (turquoise) upstream of the TSS, and genes with no TFBS upstream of $100 \mathrm{bp}$ of the TSS (blue). The relative contribution of gene clusters for (C) H4K5ac by CFC, (D) H4K12ac by CFC, and (E) mock IgG-IP with either no TFBS present in the promoter, or no TFBS, one TFBS, and multiple TFBS present upstream of $150 \mathrm{bp}$ relative to the TSS. Clusters are defined in Figures $4 \mathrm{~A}, 4 \mathrm{C}$, and $4 \mathrm{E}$, respectively.

by stereotyped TF binding in this region, approximately 100 to 200 bp upstream of the TSS [43,44]. Acetylated nucleosomes further away in the promoter, greater than $1 \mathrm{~kb}$ from the TSS, may either be more strongly bound and less easily displaced by TF binding, or they may be regulatory regions which do not depend on the presence or acetylation of nucleosomes [45]. As expected, IgG-IP control clusters were uniformly proportioned in the presence or absence of a TFBS (Figure 5E; Additional file 1: Figure S4B). Together, these data suggest that since H4K5ac is associated with increased gene expression, enrichment of H4K5ac proximal to the TSS may be a reliable marker of actively transcribed genes.

\section{Genes differentially acetylated for H4K5 are associated with fear memory in the hippocampus}

The high percentage of genes with above average H4K5ac in both FC and controls suggest that this modification is important and that it is subject to tight regulation in the context of transcription-dependent memory formation. Using a criteria-based approach, we found that $\sim 15 \%$ of genes were uniquely acetylated for $\mathrm{H} 4 \mathrm{~K} 5$ with CFC (Figure 3E), however, this did not account for differentially acetylated genes. We also found that $\mathrm{H} 4 \mathrm{~K} 5 \mathrm{ac}$ correlates to global gene expression levels. Thus, to identify specific genes induced by learning and increased H4K5ac levels in the hippocampus, we used a top-down approach - rather than identifying specific genes activated by learning through differential gene expression, we identified highly expressed genes through differential acetylation of H4K5 in FC compared to controls. We used a peak-calling algorithm to scan the genome at $300 \mathrm{bp}$ intervals for differentially acetylated regions between FC and controls. Using model-based analysis of ChIP-Seq (MACS), we obtained consensus coverage of $\mathrm{H} 4 \mathrm{~K} 5 \mathrm{ac}-\mathrm{enriched}$ regions across the mouse genome [46]. Out of 20,238 peaks identified for $\mathrm{H} 4 \mathrm{~K} 5 \mathrm{ac}$ in FC by MACS, 708 peaks were found -4000 to -2000 bp relative to the TSS, 3,370 peaks were found in the promoter ( -2000 to $0 \mathrm{bp}$ ), and 1,340 peaks were found in the CDS ( 0 to $+2000 \mathrm{bp})$. Of these, we identified 241 regions significantly acetylated for H4K5 in FC, 115 of which were associated with gene bodies representing 114 unique genes, and 126 within intergenic regions (Additional file 1: Table S2).
To validate the results obtained with MACS, we repeated the analysis with three other published algorithms for ChIP-Seq analysis, including SICER, EpiChip, and Genomatix NGS analyzer (Additional file 1: Figure S5A - 5D) [47-49]. We performed a cross-wise comparison of genes identified with the algorithms to genes identified using pre-defined criteria, including genes with more than 50 reads in the promoter (Raw H4K5), previously defined as above average, or genes with more than 50 reads in the promoter with CFC but 40 reads or less in controls (Diff H4K5), analogous to algorithmbased differential acetylation (Figure 3E; Additional file 1: Figure S5E; see Methods). Of all genes identified by MACS, approximately 70\% overlapped with SICER, the other most widely used algorithm for differential peak finding. Thus, we considered the genes identified by MACS as a reliable and representative gene set to evaluate further.

\section{Genes differentially acetylated for H4K5 in FC are associated with memory processes}

Gene ontology analysis of the 114 unique MACS-derived genes in FC identified genes enriched for structural and neuronal components including synapses, the postsynaptic density, and axons, in addition to genes involved in functional processes such as synapse assembly and organization, ion transport, calcium signaling, neuromuscular and neurological system processes (Table 1; Additional file 1: Table S2 and 4). From interaction maps, we also found that genes in pathways involved in calcium, mTOR, Erbb signaling, and Alzheimer's disease were significantly enriched (Table 2).

In contrast, the 47 genes differentially acetylated for $\mathrm{H} 4 \mathrm{~K} 5$ in controls were classified into brain processes such as negative regulation of axogenesis, of neurogenesis, and of cell development, but also contributed to normal brain development and neuronal differentiation (Table 1; Additional file 1: Table S3 and 5). Pathway analysis for genes identified in controls showed enrichment for normal neuronal processes such as axon guidance, but also for genes associated with long-term depression, a form of synaptic plasticity typically associated with synaptic weakening (Table 2). The repressive functional categories and pathways enriched in controls suggest that training counteracts these pathways for 
Table $1 \mathrm{GO}$ enrichment analysis of MACS-identified genes differentially acetylated for H4K5 in FC and control in hippocampus

\begin{tabular}{|c|c|c|c|c|}
\hline GO term & Annotation & Treatment & Fold-change & $P$-value \\
\hline GO:0045202 & Cellular component: synapse & FC & 5.78 & $8.01 \mathrm{E}-06$ \\
\hline GO:0000267 & Cellular component: cell fraction & FC & 3.48 & 7.33E-05 \\
\hline GO:0005624 & Cellular component: membrane fraction & FC & 3.76 & 0.0001 \\
\hline GO:0003008 & Biological process: system process & FC & 3.03 & 0.0002 \\
\hline GO:0015491 & Molecular function: cation:cation antiporter activity & FC & 26.05 & 0.0002 \\
\hline GO:0005626 & Cellular component: insoluble fraction & FC & 3.59 & 0.0002 \\
\hline GO:0022892 & Molecular function: substrate-specific transporter activity & FC & 2.81 & 0.0004 \\
\hline GO:0022891 & Molecular function: substrate-specific transmembrane transporter activity & FC & 2.93 & 0.0004 \\
\hline GO:0014069 & Cellular component: postsynaptic density & FC & 11.65 & 0.0004 \\
\hline GO:0007416 & Biological process: synapse assembly & FC & 18.89 & 0.0005 \\
\hline GO:0006897 & Biological process: endocytosis & FC & 5.74 & 0.0006 \\
\hline GO:0010324 & Biological process: membrane invagination & FC & 5.74 & 0.0006 \\
\hline GO:0050885 & Biological process: neuromuscular process controlling balance & FC & 16.85 & 0.0007 \\
\hline GO:0065008 & Biological process: regulation of biological quality & FC & 2.28 & 0.0008 \\
\hline GO:0050877 & Biological process: neurological system process & FC & 3.08 & 0.0008 \\
\hline GO:0022857 & Molecular function: transmembrane transporter activity & FC & 2.74 & 0.0008 \\
\hline GO:0042592 & Biological process: homeostatic process & FC & 2.85 & 0.0009 \\
\hline GO:0006810 & Biological process: transport & FC & 1.84 & 0.001 \\
\hline GO:0043062 & Biological process: extracellular structure organization & FC & 6.49 & 0.001 \\
\hline GO:0030424 & Cellular component: axon & FC & 6.38 & 0.0011 \\
\hline GO:0005583 & Cellular component: fibrillar collagen & FC & 39.19 & 0.0011 \\
\hline GO:0044456 & Cellular component: synapse part & FC & 4.92 & 0.0014 \\
\hline GO:0005246 & Molecular function: calcium channel regulator activity & FC & 32.07 & 0.0017 \\
\hline GO:0015075 & Molecular function: ion transmembrane transporter activity & FC & 2.73 & 0.0021 \\
\hline GO:0015298 & Molecular function: solute:cation antiporter activity & FC & 11.8 & 0.0021 \\
\hline GO:0005794 & Cellular component: Golgi apparatus & FC & 2.84 & 0.0025 \\
\hline GO:0015385 & Molecular function: sodium:hydrogen antiporter activity & FC & 26.05 & 0.0026 \\
\hline GO:0005451 & Molecular function: monovalent cation:hydrogen antiporter activity & FC & 26.05 & 0.0026 \\
\hline GO:0005215 & Molecular function: transporter activity & FC & 2.24 & 0.0032 \\
\hline GO:0005581 & Cellular component: collagen & FC & 19.59 & 0.0046 \\
\hline GO:0000166 & Molecular function: nucleotide binding & Control & 4.43 & $5.04 \mathrm{E}-06$ \\
\hline GO:0032553 & Molecular function: ribonucleotide binding & Control & 4.31 & 7.57E-05 \\
\hline GO:0032555 & Molecular function: purine ribonucleotide binding & Control & 4.31 & 7.57E-05 \\
\hline GO:0017076 & Molecular function: purine nucleotide binding & Control & 4.15 & 0.0001 \\
\hline GO:0005524 & Molecular function: ATP binding & Control & 4.76 & 0.0001 \\
\hline GO:0032559 & Molecular function: adenyl ribonucleotide binding & Control & 4.71 & 0.0001 \\
\hline GO:0005003 & Molecular function: ephrin receptor activity & Control & 112.59 & 0.0001 \\
\hline GO:0050771 & Biological process: negative regulation of axonogenesis & Control & 90.12 & 0.0002 \\
\hline GO:0021955 & Biological process: central nervous system neuron axonogenesis & Control & 96.56 & 0.0002 \\
\hline GO:0001883 & Molecular function: purine nucleoside binding & Control & 4.47 & 0.0002 \\
\hline GO:0030554 & Molecular function: adenyl nucleotide binding & Control & 4.49 & 0.0002 \\
\hline GO:0001882 & Molecular function: nucleoside binding & Control & 4.45 & 0.0002 \\
\hline GO:0031345 & Biological process: negative regulation of cell projection organization & Control & 71.15 & 0.0004 \\
\hline
\end{tabular}


Table $1 \mathrm{GO}$ enrichment analysis of MACS-identified genes differentially acetylated for H4K5 in FC and control in hippocampus (Continued)

\begin{tabular}{|c|c|c|c|c|}
\hline GO:0010171 & Biological process: body morphogenesis & Control & 67.59 & 0.0004 \\
\hline GO:0007492 & Biological process: endoderm development & Control & 46.61 & 0.0008 \\
\hline GO:0021954 & Biological process: central nervous system neuron development & Control & 42.24 & 0.001 \\
\hline GO:0050768 & Biological process: negative regulation of neurogenesis & Control & 39.76 & 0.0011 \\
\hline GO:0010721 & Biological process: negative regulation of cell development & Control & 37.55 & 0.0013 \\
\hline GO:0021953 & Biological process: central nervous system neuron differentiation & Control & 32.97 & 0.0017 \\
\hline GO:0030027 & Cellular component: lamellipodium & Control & 26.13 & 0.0026 \\
\hline GO:0031252 & Cellular component: cell leading edge & Control & 15.19 & 0.0076 \\
\hline GO:0044428 & Cellular component: nuclear part & Control & 3.16 & 0.0353 \\
\hline GO:0042995 & Cellular component: cell projection & Control & 3.99 & 0.0379 \\
\hline GO:0031981 & Cellular component: nuclear lumen & Control & 3.91 & 0.0399 \\
\hline GO:0005667 & Cellular component: transcription factor complex & Control & 6.25 & 0.0403 \\
\hline
\end{tabular}

Summary of GO enrichment analysis of genes differentially acetylated for H4K5 in FC over control (FC) and control over FC (Control) by MACS and using Webgestalt $\mathrm{GO}$ analysis.

* Sorted according to treatment followed by P-value, using Benjamini-Hochberg correction for multiple comparisons.

Table 2 KEGG pathways enriched in MACS-identified genes differentially acetylated for H4K5 in FC and control in hippocampus

\begin{tabular}{|c|c|c|c|}
\hline Pathway & Treatment & $\begin{array}{l}\text { Enrichment } \\
\text { ratio }\end{array}$ & $P$-value* \\
\hline O-Glycan biosynthesis & FC & 64.22 & 0.0005 \\
\hline Calcium signaling pathway & FC & 13.29 & 0.0015 \\
\hline mTOR signaling pathway & FC & 32.11 & 0.0018 \\
\hline Acute myeloid leukemia & FC & 29.48 & 0.0021 \\
\hline Alzheimer's disease & FC & 10.18 & 0.0033 \\
\hline Chronic myeloid leukemia & $\mathrm{FC}$ & 21.16 & 0.0041 \\
\hline Cardiac muscle contraction & FC & 20.43 & 0.0044 \\
\hline ErbB signaling pathway & FC & 19.34 & 0.0049 \\
\hline Fc gamma R-mediated phagocytosis & FC & 17.13 & 0.0062 \\
\hline Metabolic pathways & FC & 3.66 & 0.012 \\
\hline Axon guidance & Control & 32.99 & 0.0001 \\
\hline Calcium signaling pathway & Control & 22.59 & 0.0003 \\
\hline Regulation of actin cytoskeleton & Control & 20.2 & 0.0005 \\
\hline Long-term depression & Control & 39.19 & 0.0012 \\
\hline Gap junction & Control & 32.52 & 0.0018 \\
\hline Small cell lung cancer & Control & 32.52 & 0.0018 \\
\hline GnRH signaling pathway & Control & 29.68 & 0.0021 \\
\hline Melanogenesis & Control & 28.84 & 0.0022 \\
\hline Vascular smooth muscle contraction & Control & 22.99 & 0.0035 \\
\hline Focal adhesion & Control & 14.77 & 0.0082 \\
\hline
\end{tabular}

Summary of KEGG pathway enrichment analysis of genes differentially acetylated for H4K5 in FC over control (FC) and control over FC (Control) by MACS using Webgestalt KEGG analysis.

* Sorted according to treatment followed by P-value, using BenjaminiHochberg correction for multiple comparisons. memory formation. Alternatively, pathways upregulated in controls may be those that are needed to maintain homeostatic processes and basal neuronal functions in the absence of learning.

To validate whether genes differentially acetylated for H4K5 are also differentially expressed, we quantified mRNA expression of twelve randomly chosen genes called by MACS. mRNA levels were measured in hippocampal samples collected from animals from an independent CFC experiment to avoid sample or experimental bias associated with the ChIP-Seq. Seven out of twelve genes had significantly higher expression after CFC than in controls (Table 3). In contrast, in the cerebellum, a brain region not recruited for the formation of contextual fear memory, gene expression did not change after CFC, except for one (Table 3). Taken together, our data suggests that genes differentially acetylated for $\mathrm{H} 4 \mathrm{~K} 5$ are specific to memory formation in the hippocampus with CFC.

\section{Discussion}

The present study provides a comprehensive genomewide analysis of H4K5ac in the hippocampus following fear memory formation, and identifies a novel set of genes associated with $\mathrm{H} 4 \mathrm{~K} 5 \mathrm{ac}$ induced by learning. It demonstrates that $\mathrm{H} 4 \mathrm{~K} 5 \mathrm{ac}$ is a ubiquitous histone PTM in the genome, present on one-third of genes with above average H4K5ac in the adult mouse hippocampus. Genes associated with high $\mathrm{H} 4 \mathrm{~K} 5 \mathrm{ac}$, in both promoter and CDS, are highly expressed, but H4K5ac is most prominent within $1000 \mathrm{~kb}$ upstream of the TSS. Our results suggest that H4K5ac may be required in both the promoter and CDS, over the entire length of the gene, for transcription of full and intermediate transcripts and that the presence of $\mathrm{H} 4 \mathrm{~K} 5 \mathrm{ac}$ is a reliable marker of 
Table 3 Real-time quantitative PCR validation of MACS-identified genes differentially acetylated for H4K5 in FC over control in the hippocampus [HIP] and cerebellum [CER]

\begin{tabular}{|c|c|c|c|c|c|}
\hline Gene ID & Gene name & $\begin{array}{c}\text { Fold-change } \\
{[\mathrm{HIP}]^{*}}\end{array}$ & $\begin{array}{c}\begin{array}{c}\text { Significance } \\
{[\mathrm{HIP}]}\end{array} \\
\end{array}$ & $\begin{array}{c}\text { Fold-change } \\
\text { [CER] }\end{array}$ & $\begin{array}{c}\begin{array}{c}\text { Significance } \\
\text { [CER] }\end{array} \\
\end{array}$ \\
\hline Fbx/11 & F-box and leucine-rich repeat protein 11 [Lysine (K)-specific demethylase 2A (Kdm2a)] & $4.31 \pm 1.40$ & 0.05 & $1.04 \pm 0.05$ & NS \\
\hline Ryr3 & Ryanodine receptor 3 & $3.92 \pm 1.70$ & 0.1 & $1.10 \pm 0.51$ & NS \\
\hline Akap6 & A kinase (PRKA) anchor protein 6 & $3.77 \pm 0.71$ & 0.01 & $3.94 \pm 1.37$ & 0.05 \\
\hline Atp8a1 & ATPase, aminophospholipid transporter (APLT), class I, type 8A, member 1 & $3.35 \pm 0.46$ & 0.01 & $0.96 \pm 0.23$ & NS \\
\hline Nrxn1 & Neurexin I & $2.99 \pm 0.29$ & 0.001 & $1.21 \pm 0.58$ & NS \\
\hline Rnf220 & Ring finger protein 220 & $2.98 \pm 1.84$ & NS & $1.30 \pm 0.53$ & NS \\
\hline Kcnd2 & Potassium voltage-gated channel, Shal-related family, member 2 & $2.94 \pm 0.36$ & 0.001 & $0.46 \pm 0.11$ & NS \\
\hline Grid1 & Glutamate receptor, ionotropic, delta 1 & $2.92 \pm 0.60$ & 0.05 & $1.15 \pm 0.33$ & NS \\
\hline Col2al & Collagen, type II, alpha 1 & $2.35 \pm 0.42$ & 0.01 & $1.01 \pm 0.21$ & NS \\
\hline Serpina9 & serpin peptidase inhibitor, clade A (alpha-1 antiproteinase, antitrypsin), member 9 & $1.90 \pm 0.90$ & NS & $0.82 \pm 0.40$ & NS \\
\hline Megfi1 & Multiple EGF-like-domains 11 & $1.71 \pm 0.67$ & NS & $1.01 \pm 0.33$ & NS \\
\hline Ntrk2 & Neurotrophic tyrosine kinase, receptor, type 2 & $1.09 \pm 0.15$ & NS & $1.32 \pm 0.20$ & NS \\
\hline
\end{tabular}

* Ranked according to fold-change in HIP.

Shown as fold-change over control \pm SEM.

NS not significant.

actively transcribed genes. However, we found that enrichment of $\mathrm{H} 4 \mathrm{~K} 5 \mathrm{ac}$ in the promoter is determined, to an extent, by TF binding in which the absence of distal TFBS, 150 bp upstream of the TSS, dramatically increases $\mathrm{H} 4 \mathrm{~K} 5 \mathrm{ac}$ enrichment in the promoter. We also provide evidence that $\mathrm{H} 4 \mathrm{~K} 5 \mathrm{ac}$ may be a hallmark of activity-dependent genes that are expressed with learning. By identifying genes differentially acetylated for H4K5, we have uncovered key genes, both known and novel, involved in memory formation. These genes are specific to functions and pathways involved in synaptic plasticity and memory formation, but also to basic cellular processes, with learning.

The finding that promoters of $\sim 80 \%$ of genes are acetylated above average for $\mathrm{H} 4 \mathrm{~K} 5$ regardless of training and that, of those, two-thirds are also acetylated for H4K12, is consistent with studies of other histone PTMs. In human cell lines, for instance, the promoters of $70 \%$ of genes were enriched for both H3K9ac and H3K14ac, of which $>95 \%$ were also enriched for H3K4me3 [42]. It suggests that histone PTMs are ubiquitous in the genome, but it raises the question of whether their specificity depends on a few dominant modifications or a combination of histone PTMs, the extent to which multiple nucleosomes are modified in succession, and whether positioning of modified nucleosomes is a factor $[26,50]$. We found that $\sim 15 \%$ of genes with above average $\mathrm{H} 4 \mathrm{~K} 5 \mathrm{ac}$ are unique to $\mathrm{FC}$ and that genes differentially acetylated for $\mathrm{H} 4 \mathrm{~K} 5$ with learning are conducive to memory formation. This suggests that approximately 1000 out of 20,000 known protein-coding genes, or $5 \%$ of all genes, may be associated with memory in the hippocampus. At the moment, it is unclear what percent of genes are actively transcribed with learning, but synaptic proteins alone number 7,000 , of which the postsynaptic density comprises more than 1000 proteins [51-54].

Differential acetylation analysis suggests that learning may target memory-specific genes for hyperacetylation over those normally acetylated for H4K5 under control conditions. Our data also show that $\mathrm{H} 4 \mathrm{~K} 5 \mathrm{ac}$ is a reliable predictor of actively transcribed genes and that its level of enrichment correlates with the level of gene expression. Based on these observations, we propose that the prevalence of $\mathrm{H} 4 \mathrm{~K} 5 \mathrm{ac}$ in the promoter may be a means to prime specific genes to facilitate their expression upon training or practice for rapid stabilization of the memory trace (Figure 6). Although mature neurons and glia are fully differentiated, our notion of priming is reminiscent of gene bookmarking in mitotic cells, whereby cells retain a 'memory' for patterns of gene expression through DNA and histone modifications following exit from mitosis $[26,55,56]$. Such a priming mechanism would be advantageous for the rapid induction of memory-specific genes following learning. However, it is currently not known how nucleosomes are positioned and modified with transcriptional activity or subsequent activity over time - whether they are depleted, displaced, or their modifications altered to retain a trace of prior activity [57-60].

Consistent with the notion of priming genes with repeated learning, approximately half of the genes we identified by peak-calling are involved in cognitive processes, while the other half has not been previously associated with memory processes. For instance, Phactr3 (phosphatase and actin regulator 3), also known as Scapinin (scaffold-associated PP1-inhibiting proteins), is an interesting 


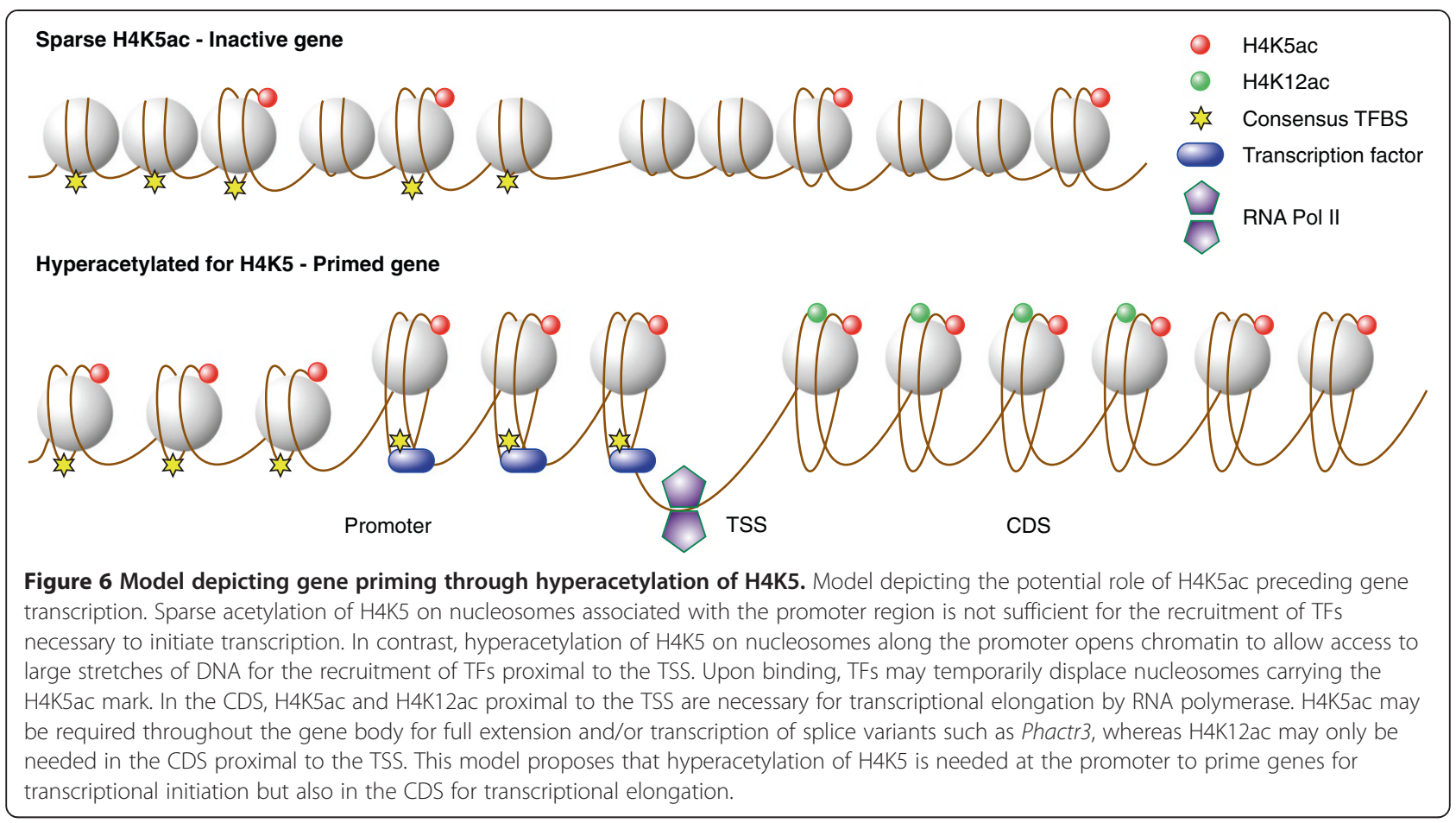

candidate with respect to memory as it is transcribed primarily in the brain and in tumors but has been relatively unstudied in the context of memory [40,61]. Likewise, $P i k 3 c d$, involved in the immune response and in cancer is implicated in the mTOR pathway with Ddit4 (also known as Redd1) and Tsc1/2. Recent studies have linked Tsc1/2 dysregulation to cognitive deficits associated with tuberous sclerosis and identified this gene as a potential target to treat autism $[62,63]$. Ddit4 has also been implicated in Alzheimer's disease and is therefore highly relevant for memory processes $[64,65]$.

A notable feature of our findings is the considerably large number of intergenic loci found to carry H4K5ac. Our observation that genic regions only accounted for one-quarter of the 20,238 peaks differentially acetylated for H4K5 suggests that, in addition to gene bodies, $\mathrm{H} 4 \mathrm{~K} 5 \mathrm{ac}$ is highly interspersed throughout intergenic regions. These regions are thought to give rise to noncoding RNAs or microRNAs that may potentially regulate genes. Indeed, the differentially acetylated targets we identified through both peak-calling algorithms and criteria-based selection methods included many known and novel noncoding RNAs. The recent discovery by the ENCODE consortium of an additional 30,000 intergenic and antisense TSS in the genome suggests that previously defined limits of what constituted genic regions, and gene annotations we used in this study, were incomplete and underestimated the activity of these novel intergenic regions [66]. Additionally, the ENCODE finding that nearly three-quarters of the genome can be transcribed at any given time, whether in genic or intergenic regions, suggests that the ubiquity of $\mathrm{H} 4 \mathrm{~K} 5 \mathrm{ac}$ is to be expected if, as in our study, H4K5ac is a modification associated with active transcription and is required to transcribe intergenic regions [66].

Finally, another important question raised by our study is whether histone PTMs participate in the recruitment of transcriptional machinery. Although low intrinsic nucleosome occupancy has been documented in promoter regulatory regions, TFBS, and origins of replication in yeast $[67,68]$, p53 was found to preferentially bind DNA sites strongly associated with nucleosomes over sites with relatively low nucleosome occupancy [69]. Our data show that actively transcribed genes with a conserved TFBS in positions proximal to the TSS have increased enrichment for H4K5ac in the promoter. Similarly, the ENCODE studies have shown that particular sets of TFs are strongly associated to proximal promoter regions and that the spatial positioning and structural motif of TFBS in these regions is highly conserved across many human cell lines [43,44]. This may suggest that nucleosomes demarcate positions of accessibility proximal to the TSS and, with appropriate modifications, open consensus sites to allow TF recruitment and binding. Other studies have shown that H3K9ac and H3K14ac are critical for the recruitment of TFIID in the promoter to initiate transcription [42,70]. Once bound, however, it is not yet known whether nucleosomes are deacetylated or evicted from the promoter of actively transcribed genes. 


\section{Conclusion}

Our study newly suggests that H4K5ac is induced in an activity-dependent manner in the adult mouse hippocampus where it may prime genes for rapid expression following repetitive learning. We propose that hyperacetylation of H4K5 proximal to the TSS in the promoter facilitates the recruitment of TFs and is associated with rapid gene expression following reinforced learning (Figure 6) [71]. Many questions still remain about chromatin remodeling and the extent to which it regulates gene expression in biological functions. However, this study provides new insight into chromatin remodeling in cognitive processes in a manner that is unbiased and independent of predefined genetic associations. Complementary genome-wide studies will be required in the future to comprehensively map the ensemble of histone modifications regulating genetic programs in cognitive and other biological processes.

\section{Methods}

\section{Animals and contextual fear conditioning}

Experiments were conducted using adult C57Bl6/J males (4-7 months old). Mice were housed under standard conditions with a 12 hour reversed light-dark cycle and access to food and water ad libitum. All animals were maintained in accordance with the Federation of Swiss Cantonal Veterinary Office and European Community Council Directive (86/609/EEC) guidelines.

Mice were habituated to the testing room and handled for three days prior to training and testing. They were then trained in a contextual fear-conditioning paradigm using a TSE Fear Conditioning System. The training consisted of a $3 \mathrm{~min}$. exposure to the conditioning context followed by a brief electric shock $(0.7 \mathrm{~mA}$ for $1 \mathrm{~s})$, then left for an additional $3 \mathrm{~min}$. in the conditioning context. Mice that were not re-conditioned were euthanized 1 hour after the initial fear-conditioning session. Mice that were to be further fear-conditioned were trained on the second day and the memory test performed 24 hours later on the third day. Single trial CFC is known to produce a robust, longlasting memory, however subsequent training has been shown to strengthen the memory and prevent random association of shock with re-exposure [6-10]. Furthermore, as re-exposure to the context on day 3 increased freezing, euthanasia was performed within one hour of the memory test on day 3, but before the 6-hour reconsolidation window and before extinction could take place $[3,29]$. The control group was handled and trained in the same manner but without a foot shock.

Comparisons between groups were analyzed by paired student's t-test or one-way ANOVA with Tukey post hoc analysis, where appropriate. GraphPad Prism was used for statistical analysis and significance was set at " $p \leq$ $0.05,{ }^{* * *} \mathrm{p} \leq 0.01$, and ${ }^{* * * *} \mathrm{p} \leq 0.001$. All data are shown as mean \pm SEM.

\section{Nuclear extraction and Western blots}

Nuclear protein extraction was performed as previously described with the following modifications [13]. Hippocampi were dissected and homogenized in $100 \mu \mathrm{l}$ nuclear inhibition buffer (NIB) at $\mathrm{pH} 7.4$ containing $3.75 \mathrm{mM}$ Tris- $\mathrm{HCl}$, $15 \mathrm{mM} \mathrm{KCl}, 3.75 \mathrm{mM} \mathrm{NaCl}, 250 \mu \mathrm{M}$ EDTA, $50 \mu \mathrm{M}$ EGTA, $30 \%(\mathrm{v} / \mathrm{v})$ glycerol, and $15 \mathrm{mM} \beta$-mercaptoethanol, with the addition of 1:200 proteinase inhibitor cocktail (SigmaAldrich), 1:500 PMSF (Sigma-Aldrich) and 1:100 phosphatase inhibitor cocktail (Sigma-Aldrich). The structures were then uniformly homogenized with a $22 \mathrm{G}$ syringe and centrifuged at 14,000 rpm for $30 \mathrm{~min}$. The supernatant and pellet, containing cytoplasmic and nuclear material, respectively, was separated and resuspended in another $100 \mu \mathrm{l}$ NIB with appropriate inhibitors. The pellet was rehomogenized with a $26 \mathrm{G}$ syringe and centrifuged at $14,000 \mathrm{rpm}$ for $30 \mathrm{~min}$.

$15 \mu \mathrm{g}$ of proteins from nuclear extracts was mixed with $4 \times$ LDS sample buffer (NuPage; Invitrogen) and 10\% $\beta$-Mercaptoethanol to a final volume of $20 \mu \mathrm{l}$ and loaded on a Novex 4-12\% Bis-Tris Gel (NuPage; Invitrogen). Proteins were then transferred onto a nitrocellulose membrane (Bio-Rad), blocked (Rockland IR blocking buffer; Rockland Immunochemicals), and incubated with primary and secondary antibodies. Whole purified histones were run in parallel to confirm histone subunits (ImmunoVision) and Precision Plus protein dual color standards were used to determine molecular weights (Bio-Rad Laboratories). Bands were identified and quantified using an Odyssey IR scanner (LI-COR Biosciences) and the H4K5ac (11 kDa) signal was normalized to $\beta$-actin $(42 \mathrm{kDa})$. Primary antibodies used were anti-acetyl H4K5 [72] (1:1000; Millipore) and monoclonal $\beta$-actin (1:1000; Sigma-Aldrich); secondary antibodies used were goat-anti-rabbit (IRDye $680 \mathrm{~nm}$; 1:10,000) and goat-anti-mouse (IRDye $800 \mathrm{~nm} ; 1: 10,000$; LI-COR Biosciences).

\section{Quantitative real-time PCR}

Total RNA was extracted from hippocampus using TRIzol reagent and $1 \mu \mathrm{g}$ of RNA was reverse-transcribed using the SuperScript First Strand Synthesis II system (Invitrogen). Equal amounts of cDNA from each sample were run in duplicate along with an endogenous control, Gapdh, on a Light Cycler 480 (Roche AG). Crossing point $(\mathrm{Cp})$ values, which are more reliable and reproducible than $\mathrm{Ct}$ values, were obtained using the second derivative maximum method (Roche AG). Comparative analysis on $\mathrm{Cp}$ values was performed and expressed as fold change over the average of controls [73]. Mean and SEM values were obtained for each and analyzed using two-tailed paired t-tests to determine statistical significance $(p<0.05)$. Oligonucleotides used for quantitative real-time PCR are listed in (Additional file 1: Table S6). 


\section{Chromatin immunoprecipitation}

Chromatin immunoprecipitation (ChIP) was performed as previously described [13], with the following modifications. Briefly, three hippocampal samples for each group were individually cross-linked with $1 \%$ formaldehyde, quenched with $0.125 \mathrm{M}$ glycine, and spun down at $1500 \mathrm{rpm}$ for $5 \mathrm{~min}$ at $4^{\circ} \mathrm{C}$. To isolate chromatin, samples were washed and homogenized in $2 \mathrm{ml}$ cell lysis buffer containing proteinase and phosphatase inhibitors with a Dounce homogenizer. Samples were centrifuged at $4000 \mathrm{rpm}$ for $5 \mathrm{~min}$. and homogenized again in $1 \mathrm{ml}$ nuclear lysis buffer with inhibitors. DNA was sheared using a Baendelin Sono Plus to a fragment length of 600-800 bp. Total genomic DNA (input) was quantified and $80 \mu \mathrm{g}$ of chromatin from each sample was immunoprecipitated overnight at $4^{\circ} \mathrm{C}$ with either $5 \mu \mathrm{l}$ of anti-acetyl-H4K5 (07-327; Millipore) or $5 \mu \mathrm{l}$ of IgG (17-685; Millipore) as a negative control. After incubation, nucleosome complexes were isolated with $60 \mu \mathrm{l}$ of protein A agarose/salmon sperm DNA slurry (Millipore) for $1 \mathrm{~h}$ at $4^{\circ} \mathrm{C}$. The complexes were washed and dissociated from the beads by incubation in 1\% SDS in TE and nuclear lysis buffer at $65^{\circ} \mathrm{C}$ for $10 \mathrm{~min}$. Histones were then digested with proteinase $\mathrm{K}$ for $1 \mathrm{~h}$ at $45^{\circ} \mathrm{C}$ and the DNA was finally extracted with phenol/chloroform/isoamyl alcohol and ethanol precipitation. DNA concentrations were measured on a Nanodrop (Thermo Fisher Scientific) and further verified on a Qubit fluorometer (Invitrogen). Uniformity of fragment size and quality control was validated on a 2100 BioAnalyzer (Agilent Technologies).

\section{ChIP-Seq library preparation}

Library preparation was according to recommended guidelines (Life Technologies). From both ChIP and input control samples, $200 \mathrm{ng}$ of DNA was further sonicated at $4^{\circ} \mathrm{C}$ to a mean fragment size of between 100 to $150 \mathrm{bp}$ using the Covaris S2 sonicator. The DNA was then end-repaired using end-polishing enzymes such that damaged DNA with protruding $5^{\prime}$ or $3^{\prime}$ ends were blunt-ended and phosphorylated. Following repair, the samples were purified using a column purification kit and the blunt ends were ligated with $1 \mu \mathrm{l}$ of multiplex adaptors. The ligated samples were then nick translated and amplified according to the SOLiD Fragment Library Barcoding protocol and column purified separately. The libraries were then quantitated using a Qubit fluorometer. $20 \mu \mathrm{l}$ of each library was sizeselected for ligation products of $170-230$ bp using $2 \%$ E-gels and pooled following gel purification. Finally, equimolar amounts of each barcoded library were mixed together before ePCR followed by sequencing.

\section{SOLiD sequencing and mapping statistics}

Sequencing was performed on an Applied Biosystems SOLiD 3 platform. Image acquisition and base calling was automated on the SOLiD Instrument Control Software system. The color space reads were mapped and aligned to the current assembly of the mouse genome ( $\mathrm{mm} 9$, NCBI Build 37 dating July 2007; UCSC genome browser) using the mapping tool of the Bioscope v1.2.1 software suite (Applied Biosystems). Only reads with a maximum of 4 failed color calls and quality values larger than 8 were considered for contiguous mapping. The reads were mapped allowing a maximum of 6 color mismatches and reads with up to 10 mappings on the genome were reported in a SAM file. This file was used for subsequent identification of enriched regions. Sequence data from this study has been submitted to NCBI Gene Expression Omnibus database (http://www.ncbi.nlm.nih.gov/geo/) and assigned the identifier (accession no. GSE30325).

From a total of 309 million $(309,346,614)$ 50-bp ChIP-seq reads, 230 million $(229,838,436$; $74.3 \%)$ were uniquely mapped to the current mouse reference genome with a mismatch allowance of $\leq 6$ per 50 consecutive bases (Additional file 1: Table S1). The total number of sequenced reads was equivalent to $\sim 6.2$ complete mouse genomes $(15.5 \mathrm{~Gb})$, while the mappable reads were equivalent to $\sim 4.6$ genomes (11.5 Gb). We obtained an average of $\sim 45$ reads per promoter region, 783 and 894 reads per CDS for FC and control, respectively, with lower read counts for mock IgGimmunoprecipitated (IgG-IP) control samples (12 and 10 reads per promoter, 287 and 245 reads per CDS for FC and control, respectively) (Additional file 1: Table S1). An equivalent H4K12ac ChIP-seq dataset from Peleg et al. was obtained from Galaxy-Central (sm1186088) at <main.g2.bx. psu.edu/u/fischerlab/h/sm1186088> and re-analyzed using our workflow. With the H4K12ac dataset, we obtained 5.53 million total reads, of which 4.04 million were unique reads (73.1\%) with an average coverage of 8.7 reads per promoter and 123 reads per CDS (Additional file 1: Table S1). The higher sequence coverage of $\mathrm{H} 4 \mathrm{~K} 5 \mathrm{ac}$ in control, $13.3 \%$ more mapped reads (4.9 million reads) compared to FC, may account for the larger number of genes identified in control with our exclusion criteria ( $>50$ reads). The lower coverage (5.53 million reads in total) in H4K12ac may also explain the smaller percentage of genes found to overlap with H4K5ac.

\section{Differential peak calling and data mining analysis}

Peak finding was performed using a Model-based Analysis of ChIP-Seq (MACS, version 1.3.7.1 - Oktoberfest) algorithm [46]. To determine genes differentially enriched for $\mathrm{H} 4 \mathrm{~K} 5 \mathrm{ac}$ in the respective groups, we ran MACS on fear-conditioned against non-fearconditioned control and vice versa. H4K5ac peaks were identified in MACS with the following parameters: effective genome size $=1.87 \mathrm{e}+09$, tag size $=50$, bandwidth $=300, \mathrm{~m}$-fold $=4$, and P-value cutoff $=$ 1.00e-5. We also used the Statistical model for the 
Identification of chip-Enriched Regions (SICER, version 1.1) to call differentially acetylated peaks between groups [47]. We used the following parameters for SICER: redundancy threshold $=1$, window size $=200$, fragment size $=150$, effective genome fraction $=0.7$, gap size $=400$, FDR $=1.00 \mathrm{e}-3$, and filtered postanalysis for genes with P-value $=1.00 \mathrm{e}-5$. We further compared results to the Genomatix NGS analyzer with Auto-Claverie algorithm with the following parameters: window size $=100$ and $\mathrm{P}$-value $=0.05$, filtered postanalysis for genes with P-value $=1.00 \mathrm{e}-5$ [49]. EpiChip analysis was performed according to standard protocols (epichip.sourceforge.net), except gene scoring was performed \pm 5000 from the 5 ' start position [48]. H4K12ac ChIP-Seq data, by CFC in young mice, was obtained from

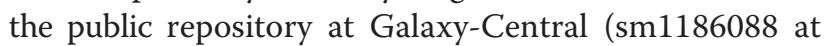
$<$ main.g2.bx.psu.edu/u/fischerlab/h/sm1186088>). Control ChIP-Seq data for H4K12ac, for sample or experimental condition, was not available [4].

\section{Gene ontology and pathway analysis}

To determine functional gene enrichment and interaction networks of genes differentially acetylated in fear-conditioned compared to non-fear-conditioned controls, we used the genes identified in MACS for functional annotation. From the 241 differentially acetylated regions identified in fear-conditioned over control, 115 unique peaks were associated in the promoter or coding region of genes. From the 77 differentially acetylated regions identified in control over fear-conditioned, 42 unique peaks were associated with gene bodies. We used The Database for Annotation, Visualization and Integrated Discovery (DAVID, v6.7; http://david.abcc.ncifcrf. gov) for the analysis of functionally-enriched genes in our respective gene lists [74]. Settings were set at a count threshold of 2 and EASE score of 0.1, a more conservative test than Fisher's Exact test. We also used Web-based Gene Set Analysis Toolkit V2 (WebGestalt; http://bioinfo. vanderbilt.edu/webgestalt) for the analysis of functionallyenriched genes in our respective gene lists [75]. Genes were analyzed using a hypergeometric test with multiple adjustment using the method of Benjamini \& Hochberg and categorized into their respective classes or pathway associations based on the Kyoto Encyclopedia of Genes and Genomes (KEGG; http://www.genome.jp/kegg/ kegg2.html).

\section{Gene expression analysis}

Gene expression data was obtained from the Gene Expression Omnibus repository at NCBI (http://www.ncbi.nlm. nih.gov/geo/query/acc.cgi?acc=GSE20270), and processed and analyzed with R/Bioconductor. Spot intensities were normalized using quantile normalization. For the comparison with the acetylation levels, the genes were subdivided in ten equally sized bins according to the average expression.

\section{Transcription factor binding site analysis}

Known transcription factor binding sites (TFBS) were downloaded from the CisRED database [76]. A total of 223,000 binding sites was used to analyze whether the presence of a known TFBS at a given position in the promoter determines the acetylation level at that position. Genes were divided into expressed and unexpressed genes, and expressed genes were further subdivided into two groups depending on whether a TFBS was annotated at that position. For each group we computed the percentage of genes acetylated at position $\times$ in step widths of 10 , from 0 to 2000 bp upstream of the TSS.

\section{Acetylation profile clustering}

We computed acetylation profiles in the $\pm 2 \mathrm{~kb}$ region around the transcription start site (TSS) and used k-means clustering to subdivide the profiles into 5 clusters. We subsequently built cross-tabulation tables to check whether cluster membership correlates with the expression level and/or with the presence of a known TFBS in certain regions. Clusters were generated in an unsupervised fashion and correlation between acetylation scores and gene expression was computed using Spearman's rank correlation.

\section{Additional file}

Additional file 1: Supplementary figures and tables. This file contains Supplementary Figures 1 to 5 and Supplementary Tables 1 to 6.

\section{Abbreviations}

CDS: Coding sequence; CFC: Contextual fear conditioning;

ChIP-Seq: Chromatin immunoprecipitation followed by sequencing;

ChIP: Chromatin immunoprecipitation; Cp: Crossing point; DAVID: The database for annotation, visualization and integrated discovery; FC: Fear conditioning; FDR: False discovery rate; GO: Gene ontology; H2BK5ac: Histone $\mathrm{H} 2 \mathrm{~B}$ lysine 5 acetylation; H2BK12ac: Histone H2B lysine 12 acetylation; H2BK15ac: Histone H2B lysine 15 acetylation; H2BK20ac: Histone H2B lysine20 acetylation; H3K14ac: Histone H3 lysine 14 acetylation; H3K9ac: Histone H3 lysine 9 acetylation; H4K12ac: Histone H4 lysine 12 acetylation; H4K5ac: Histone H4 lysine 5 acetylation; H4K8ac: Histone H4 lysine 8 acetylation; HDAC: Histone deacetylases; IgG-IP: IgG-immunoprecipitated; KEGG: Kyoto encyclopedia of genes and genomes; MACS: Model-based analysis of ChIP-Seq; PCR: Polymerase chain reaction; PP1: Protein phosphatase 1; PTM: Posttranslational modification; SAHA: Suberoylanilide hydroxamic acid; SICER: Statistical model for the identification of chipenriched regions; TF: Transcription factor; TFBS: Transcription factor binding site; TSS: Transcription start site; TTS: Transcription termination site;

UTR: Untranslated region; WebGestalt: Web-based gene set analysis toolkit V2.

\section{Competing interests}

The authors declare they have no competing interests.

\section{Authors' contributions}

CSP initiated and designed the study. CSP performed and/or oversaw fear conditioning experiments, ChIP for sequencing, peak-finding analysis, raw data analysis, GO analysis, RT-PCR validations, and wrote the manuscript. HR provided analysis of mapped reads, sequence read annotation and classification, gene expression correlation, and transcription factor binding 
site analysis. IMM provided interpretation of the data and critical revision of the manuscript. All authors have read and approved the manuscript.

\section{Acknowledgements}

We thank Sirisha Aluri and Rémy Bruggman for SOLiD sequencing support, Francesca Manuella for Western blots, Amandine Valomon for discussions on gene analysis, Johannes Graeff for ChIP advice, and Hans Welzl for discussions on behavior. The laboratory of IMM is supported by the University of Zürich, the Swiss Federal Institute of Technology, the Swiss National Science Foundation, the National Center for Competence in Research "Neural Plasticity and Repair."

\section{Author details}

'Department of Health Science and Technology, ETH Zürich, Zürich, Switzerland. 'Functional Genomics Center of Zürich, Zürich, Switzerland. ${ }^{3}$ Brain Research Institute, Medical Faculty of the University of Zürich, Zürich, Switzerland.

Received: 21 January 2013 Accepted: 3 August 2013

Published: 8 August 2013

\section{References}

1. Taubenfeld SM, Milekic MH, Monti B, Alberini CM: The consolidation of new but not reactivated memory requires hippocampal C/EBPbeta. Nat Neurosci 2001, 4:813-818.

2. Kandel ER: The molecular biology of memory storage: a dialogue between genes and synapses. Science 2001, 294:1030-1038.

3. Levenson JM, Choi S, Lee SY, Cao YA, Ahn HJ, Worley KC, Pizzi M, Liou HC, Sweatt JD: A bioinformatics analysis of memory consolidation reveals involvement of the transcription factor c-rel. J Neurosci 2004, 24:3933-3943.

4. Peleg S, Sananbenesi F, Zovoilis A, Burkhardt S, Bahari-Javan S, Agis-Balboa RC, Cota P, Wittnam JL, Gogol-Doering A, Opitz L, et al: Altered histone acetylation is associated with age-dependent memory impairment in mice. Science 2010, 328:753-756.

5. Rowe WB, Blalock EM, Chen KC, Kadish I, Wang D, Barrett JE, Thibault O, Porter NM, Rose GM, Landfield PW: Hippocampal expression analyses reveal selective association of immediate-early, neuroenergetic, and myelinogenic pathways with cognitive impairment in aged rats. J Neurosci 2007, 27:3098-3110.

6. Inda MC, Muravieva EV, Alberini CM: Memory retrieval and the passage of time: from reconsolidation and strengthening to extinction. The Journal of neuroscience: the official journal of the Society for Neuroscience 2011, 31:1635-1643

7. Lee JL: Memory reconsolidation mediates the strengthening of memories by additional learning. Nat Neurosci 2008, 11:1264-1266

8. Bergado JA, Almaguer-Melian W, Kostenko S, Frey S, Frey JU: Behavioral reinforcement of long-term potentiation in rat dentate gyrus in vivo is protein synthesis-dependent. Neuroscience letters 2003, 351:56-58.

9. Lubin FD, Sweatt JD: The IkappaB kinase regulates chromatin structure during reconsolidation of conditioned fear memories. Neuron 2007, 55:942-957.

10. Miller CA, Sweatt JD: Covalent modification of DNA regulates memory formation. Neuron 2007, 53:857-869.

11. Chwang WB, Arthur JS, Schumacher A, Sweatt JD: The nuclear kinase mitogenand stress-activated protein kinase 1 regulates hippocampal chromatin remodeling in memory formation. J Neurosci 2007, 27:12732-12742.

12. Guan JS, Haggarty SJ, Giacometti E, Dannenberg JH, Joseph N, Gao J, Nieland $T J$, Zhou Y, Wang X, Mazitschek R, et al: HDAC2 negatively regulates memory formation and synaptic plasticity. Nature 2009, 459:55-60.

13. Koshibu K, Graff J, Beullens M, Heitz FD, Berchtold D, Russig H, Farinelli M, Bollen M, Mansuy IM: Protein phosphatase 1 regulates the histone code for long-term memory. The Journal of Neuroscience: the Official Journal of the Society for Neuroscience 2009, 29:13079-13089.

14. Miller CA, Campbell SL, Sweatt JD: DNA methylation and histone acetylation work in concert to regulate memory formation and synaptic plasticity. Neurobiol Learn Mem 2008, 89:599-603.

15. Juliandi $B$, Abematsu M, Nakashima $K$ : Chromatin remodeling in neural stem cell differentiation. Current opinion in neurobiology 2010, 20:408-415.

16. Barski A, Jothi R, Cuddapah S, Cui K, Roh TY, Schones DE, Zhao K: Chromatin poises miRNA- and protein-coding genes for expression. Genome research 2009, 19:1742-1751.
17. Bell O, Tiwari VK, Thoma NH, Schubeler D: Determinants and dynamics of genome accessibility. Nature reviews Genetics 2011, 12:554-564.

18. Koshibu K, Graff J, Mansuy IM: Nuclear protein phosphatase-1: an epigenetic regulator of fear memory and amygdala long-term potentiation. Neuroscience 2011, 173:30-36.

19. Bousiges O, Neidl R, Majchrzak M, Muller MA, Barbelivien A, de Pereira Vasconcelos A, Schneider A, Loeffler JP, Cassel JC, Boutillier AL: Detection of histone acetylation levels in the dorsal hippocampus reveals early tagging on specific residues of $\mathrm{H} 2 \mathrm{~B}$ and $\mathrm{H} 4$ histones in response to learning. PloS one 2013, 8:e57816.

20. Bredy TW, Barad M: The histone deacetylase inhibitor valproic acid enhances acquisition, extinction, and reconsolidation of conditioned fear. Learn Mem 2008, 15:39-45.

21. Alarcon JM, Malleret G, Touzani K, Vronskaya S, Ishii S, Kandel ER, Barco A: Chromatin acetylation, memory, and LTP are impaired in CBP+/- mice: a model for the cognitive deficit in Rubinstein-Taybi syndrome and its amelioration. Neuron 2004, 42:947-959.

22. Vecsey CG, Hawk JD, Lattal KM, Stein JM, Fabian SA, Attner MA, Cabrera SM, McDonough CB, Brindle PK, Abel T, Wood MA: Histone deacetylase inhibitors enhance memory and synaptic plasticity via CREB:CBPdependent transcriptional activation. The Journal of neuroscience: the official journal of the Society for Neuroscience 2007, 27:6128-6140.

23. Bredy TW, Wu H, Crego C, Zellhoefer J, Sun YE, Barad M: Histone modifications around individual BDNF gene promoters in prefrontal cortex are associated with extinction of conditioned fear. Learn Mem 2007, 14:268-276.

24. Kilgore M, Miller CA, Fass DM, Hennig KM, Haggarty SJ, Sweatt JD, Rumbaugh G: Inhibitors of class 1 histone deacetylases reverse contextual memory deficits in a mouse model of Alzheimer's disease. Neuropsychopharmacology: official publication of the American College of Neuropsychopharmacology 2010, 35:870-880.

25. Ricobaraza A, Cuadrado-Tejedor M, Marco S, Perez-Otano I, Garcia-Osta A Phenylbutyrate rescues dendritic spine loss associated with memory deficits in a mouse model of Alzheimer disease. Hippocampus 2012, 22:1040-1050.

26. Zhao R, Nakamura T, Fu Y, Lazar Z, Spector DL: Gene bookmarking accelerates the kinetics of post-mitotic transcriptional re-activation. Nature cell biology 2011, 13:1295-1304.

27. Gale GD, Anagnostaras SG, Godsil BP, Mitchell S, Nozawa T, Sage JR, Wiltgen B, Fanselow MS: Role of the basolateral amygdala in the storage of fear memories across the adult lifetime of rats. J Neurosci 2004, 24:3810-3815.

28. Fanselow MS: Factors governing one-trial contextual conditioning Anim Learn Behav 1990, 18:264-270.

29. Monfils MH, Cowansage KK, Klann E, LeDoux JE: Extinction-reconsolidation boundaries: key to persistent attenuation of fear memories. Science 2009, 324:951-955.

30. Nader K, Schafe GE, LeDoux JE: The labile nature of consolidation theory. Nature Reviews Neuroscience 2000, 1:216-219.

31. Sara SJ: Retrieval and reconsolidation: toward a neurobiology of remembering. Learn Mem 2000, 7:73-84.

32. Alberini $\mathrm{CM}$ : The role of reconsolidation and the dynamic process of longterm memory formation and storage. Front Behav Neurosci 2011, 5:12.

33. Chwang WB, O'Riordan KJ, Levenson JM, Sweatt JD: ERK/MAPK regulates hippocampal histone phosphorylation following contextual fear conditioning. Learn Mem 2006, 13:322-328.

34. Wang Z, Zang C, Rosenfeld JA, Schones DE, Barski A, Cuddapah S, Cui K, Roh TY, Peng W, Zhang MQ, Zhao K: Combinatorial patterns of histone acetylations and methylations in the human genome. Nat Genet 2008, 40:897-903.

35. Dudai Y: The restless engram: consolidations never end. Annu Rev Neurosci 2012, 35:227-247.

36. Kurdistani SK, Tavazoie S, Grunstein M: Mapping global histone acetylation patterns to gene expression. Cell 2004, 117:721-733.

37. Kouzarides T: Chromatin modifications and their function. Cell 2007, 128:693-705.

38. Li B, Carey M, Workman JL: The role of chromatin during transcription. Cell 2007, 128:707-719.

39. Anderson VE, Prudden J, Prochnik S, Giddings TH Jr, Hardwick KG: Novel sfi1 alleles uncover additional functions for Sfi1p in bipolar spindle assembly and function. Molecular Biology of the Cell 2007, 18:2047-2056. 
40. Sagara J, Arata T, Taniguchi S: Scapinin, the protein phosphatase 1 binding protein, enhances cell spreading and motility by interacting with the actin cytoskeleton. PloS one 2009, 4:e4247

41. Teif VB, Rippe K: Statistical-mechanical lattice models for protein-DNA binding in chromatin. Journal of physics Condensed matter: an Institute of Physics journal 2010, 22:414105

42. Guenther MG, Levine SS, Boyer LA, Jaenisch R, Young RA: A chromatin landmark and transcription initiation at most promoters in human cells. Cell 2007, 130:77-88

43. Bernstein BE, Birney E, Dunham I, Green ED, Gunter C, Snyder M: An integrated encyclopedia of DNA elements in the human genome. Nature 2012, 489:57-74.

44. Neph S, Vierstra J, Stergachis AB, Reynolds AP, Haugen E, Vernot B, Thurman RE, John S, Sandstrom R, Johnson AK, et al: An expansive human regulatory lexicon encoded in transcription factor footprints. Nature 2012, 489:83-90.

45. Thurman RE, Rynes E, Humbert R, Vierstra J, Maurano MT, Haugen E, Sheffield NC, Stergachis AB, Wang H, Vernot B, et al: The accessible chromatin landscape of the human genome. Nature 2012, 489:75-82.

46. Zhang Y, Liu T, Meyer CA, Eeckhoute J, Johnson DS, Bernstein BE, Nusbaum C, Myers RM, Brown M, Li W, Liu XS: Model-based analysis of ChIP-Seq (MACS). Genome Biol 2008, 9:R137.

47. Zang C, Schones DE, Zeng C, Cui K, Zhao K, Peng W: A clustering approach for identification of enriched domains from histone modification ChIP-Seq data. Bioinformatics 2009, 25:1952-1958.

48. Hebenstreit D, Gu M, Haider S, Turner DJ, Lio P, Teichmann SA: EpiChIP: gene-by-gene quantification of epigenetic modification levels. Nucleic acids research 2011, 39:e27.

49. Sultan M, Schulz MH, Richard H, Magen A, Klingenhoff A, Scherf M, Seifert M, Borodina T, Soldatov A, Parkhomchuk D, et al: A global view of gene activity and alternative splicing by deep sequencing of the human transcriptome. Science 2008, 321:956-960

50. Sarge KD, Park-Sarge OK: Gene bookmarking: keeping the pages open. Trends in Biochemical Sciences 2005, 30:605-610.

51. Butko MT, Savas JN, Friedman B, Delahunty C, Ebner F, Yates JR 3rd, Tsien RY: In vivo quantitative proteomics of somatosensory cortical synapses shows which protein levels are modulated by sensory deprivation. Proc Natl Acad Sci USA 2013, 110:E726-735.

52. Collins MO, Yu L, Coba MP, Husi H, Campuzano I, Blackstock WP, Choudhary JS, Grant SG: Proteomic analysis of in vivo phosphorylated synaptic proteins. J Biol Chem 2005, 280:5972-5982.

53. Yoshimura Y, Yamauchi Y, Shinkawa T, Taoka M, Donai H, Takahashi N, Isobe T, Yamauchi T: Molecular constituents of the postsynaptic density fraction revealed by proteomic analysis using multidimensional liquid chromatography-tandem mass spectrometry. J Neurochem 2004, 88:759-768.

54. Bayes A, van de Lagemaat LN, Collins MO, Croning MD, Whittle IR, Choudhary JS, Grant SG: Characterization of the proteome, diseases and evolution of the human postsynaptic density. Nat Neurosci 2011, 14:19-21.

55. Sarge KD, Park-Sarge OK: Mitotic bookmarking of formerly active genes: keeping epigenetic memories from fading. Cell cycle 2009, 8:818-823.

56. Zaidi SK, Young DW, Montecino MA, Lian JB, van Wijnen AJ, Stein JL, Stein GS: Mitotic bookmarking of genes: a novel dimension to epigenetic control. Nat Rev Genet 2010, 11:583-589.

57. Goh WS, Orlov Y, Li J, Clarke ND: Blurring of high-resolution data shows that the effect of intrinsic nucleosome occupancy on transcription factor binding is mostly regional, not local. PLoS Comput Biol 2010, 6:e1000649.

58. Jiang C, Pugh BF: Nucleosome positioning and gene regulation: advances through genomics. Nat Rev Genet 2009, 10:161-172.

59. Sadeh R, Allis CD: Genome-wide "re"-modeling of nucleosome positions. Cell 2011, 147:263-266

60. Tillo D, Kaplan N, Moore IK, Fondufe-Mittendorf Y, Gossett AJ, Field Y, Lieb JD, Widom J, Segal E, Hughes TR: High nucleosome occupancy is encoded at human regulatory sequences. PloS one 2010, 5:e9129.

61. Farghaian H, Chen Y, Fu AW, Fu AK, Ip JP, Ip NY, Turnley AM, Cole AR: Scapinin-induced inhibition of axon elongation is attenuated by phosphorylation and translocation to the cytoplasm. The Journal of Biological Chemistry 2011, 286:19724-19734.
62. Ehninger D, de Vries PJ, Silva AJ: From mTOR to cognition: molecular and cellular mechanisms of cognitive impairments in tuberous sclerosis. Journal of Intellectual Disability Research: JIDR 2009, 53:838-851.

63. Ehninger D, Silva AJ: Rapamycin for treating Tuberous sclerosis and autism spectrum disorders. Trends in Molecular Medicine 2011, 17:78-87.

64. Morel M, Couturier J, Pontcharraud R, Gil R, Fauconneau B, Paccalin M, Page G: Evidence of molecular links between PKR and mTOR signalling pathways in Abeta neurotoxicity: role of p53, Redd1 and TSC2. Neurobiology of Disease 2009, 36:151-161.

65. Damjanac M, Page G, Ragot S, Laborie G, Gil R, Hugon J, Paccalin M: PKR, a cognitive decline biomarker, can regulate translation via two consecutive molecular targets p53 and Redd1 in lymphocytes of AD patients. Journal of Cellular and Molecular Medicine 2009, 13:1823-1832.

66. Djebali S, Davis CA, Merkel A, Dobin A, Lassmann T, Mortazavi A, Tanzer A, Lagarde J, Lin W, Schlesinger F, et al: Landscape of transcription in human cells. Nature 2012, 489:101-108.

67. Kaplan N, Moore IK, Fondufe-Mittendorf Y, Gossett AJ, Tillo D, Field Y, LeProust EM, Hughes TR, Lieb JD, Widom J, Segal E: The DNA-encoded nucleosome organization of a eukaryotic genome. Nature 2009, 458:362-366.

68. Field Y, Kaplan N, Fondufe-Mittendorf Y, Moore IK, Sharon E, Lubling Y, Widom J, Segal E: Distinct modes of regulation by chromatin encoded through nucleosome positioning signals. PLOS Comput Biol 2008, 4:e1000216.

69. Lidor Nili E, Field Y, Lubling Y, Widom J, Oren M, Segal E: p53 binds preferentially to genomic regions with high DNA-encoded nucleosome occupancy. Genome Res 2010, 20:1361-1368.

70. Agalioti T, Chen G, Thanos D: Deciphering the transcriptional histone acetylation code for a human gene. Cell 2002, 111:381-392.

71. Albert I, Mavrich TN, Tomsho LP, Qi J, Zanton SJ, Schuster SC, Pugh BF: Translational and rotational settings of H2A.Z nucleosomes across the Saccharomyces cerevisiae genome. Nature 2007, 446:572-576.

72. Zippo A, Serafini R, Rocchigiani M, Pennacchini S, Krepelova A, Oliviero S: Histone crosstalk between H3S10ph and H4K16ac generates a histone code that mediates transcription elongation. Cell 2009, 138:1122-1136.

73. Livak KJ, Schmittgen TD: Analysis of relative gene expression data using real-time quantitative PCR and the 2(-Delta Delta $C(T)$ ) Method. Methods 2001, 25:402-408.

74. da Huang W, Sherman BT, Lempicki RA: Systematic and integrative analysis of large gene lists using DAVID bioinformatics resources. Nature Protocols 2009, 4:44-57.

75. Zhang B, Kirov S, Snoddy J: WebGestalt: an integrated system for exploring gene sets in various biological contexts. Nucleic Acids Res 2005 33:W741-748.

76. Robertson G, Bilenky M, Lin K, He A, Yuen W, Dagpinar M, Varhol R, Teague K, Griffith OL, Zhang X, et al: cisRED: a database system for genome-scale computational discovery of regulatory elements. Nucleic Acids Res 2006, 34:D68-73.

doi:10.1186/1471-2164-14-539

Cite this article as: Park et al.: Genome-wide analysis of H4K5 acetylation associated with fear memory in mice. BMC Genomics 2013 14:539.

\section{Submit your next manuscript to BioMed Central and take full advantage of:}

- Convenient online submission

- Thorough peer review

- No space constraints or color figure charges

- Immediate publication on acceptance

- Inclusion in PubMed, CAS, Scopus and Google Scholar

- Research which is freely available for redistribution 